Journal of Sustainable Development of Transport and Logistics

journal home page: https://jsdtl.sciview.net

\begin{tabular}{|c|c|}
\hline $\begin{array}{l}\text { Journal of } \\
\text { Sustainable } \\
\text { WBevelopment of } \\
\text { Transport and } \\
\text { Wogistics }\end{array}$ & $\begin{array}{l}\text { Jahangiri, S., Nikolova, N., \& Tenekedjiev, K. (2018). Empirical testing of inventories } \\
\text { applying on-board measurements of exhaust emissions at port and at sea. Journal of } \\
\text { Sustainable Development of Transport and Logistics, 3(2), 6-33. doi:10.14254/jsdtl.2018.3- } \\
\text { 2.1. }\end{array}$ \\
\hline
\end{tabular}

\title{
Empirical testing of inventories applying on-board measurements of exhaust emissions at port and at sea
}

\author{
Sanaz Jahangiri ${ }^{1}$ (D), Natalia Nikolova ${ }^{1,2}$ (D), Kiril Tenekedjiev 1,2 (D)
}

\author{
${ }^{1}$ Australian Maritime College, University of Tasmania, \\ Launceston, Tasmania, Australia \\ 2 Nikola Vaptsarov Naval Academy, \\ Varna, Bulgaria
}

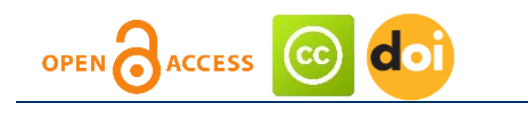

Article history:

Received: June 10, 2018

1st Revision: August 20,

2018

Accepted: October 25, 2018

\section{DOI:}

10.14254/jsdtl.2018.3-2.1

\begin{abstract}
We present a comprehensive case study to identify the best vessel-specific inventory family that predicts the primary emissions from an ocean-going vessel when at berth, while maneuvering and while cruising. The main purpose of the paper is to generalize the implication of the case study by advising a novel policy, which will allow different authorities to estimate the shipping emissions in a cost-effective and reliable way. The emissions rates of nitrogen oxides, sulphur oxides, carbon dioxide, carbon monoxide, hydrocarbon, and particulate matter from the main engine and from the auxiliary engines are measured for different modes of ship operations in an on-board experiment campaign. The measured total emission amounts were predicted with 13 families of emission inventories and prediction deviations have been calculated. A procedure was advised for estimating the prediction inventory deviations of the combined hourly emission amounts from the main engine plus the auxiliary engines. Each inventory family has been formalized as a six-dimensional vector of prediction deviations for any mode of operation. The best vessel-specific inventory families were identified using the minimal mean absolute deviation criteria. A more rational procedure to rank inventories is considered, which treats the missing value problem and constructs a six-attribute value function. The use of preferential analysis and value functions further clarifies the recommended choice of inventory method. In this case study we demonstrated that the most suitable inventory families will provide reliable predictions with acceptable deviations from the measured emissions. At berth and for maneuvering, the best inventory family turned out to be MOPSEA (with $32.2 \%$ and $39.6 \%$ mean absolute deviations respectively). For cruising, the most precise inventory family is MEET (with $59.2 \%$ mean absolute deviation), whereas MOPSEA being the third best. However, some of the other inventories produce unacceptably high deviation, well above $100 \%$. The practical implication is that while inventory methods can produce precise and cost-effective predictions, they should never be used without experimental verification. That is why, we provide an algorithm to use on-board experimental measurements to identify the best vessel-specific inventory family, which predicts the primary emission of a ship at a given mode of operation. The proposed algorithm and the implications of the case study are utilized to motivate a proposal for a novel future policy for a costeffective and reliable emission estimation from shipping.
\end{abstract}

Keywords: Emission pollution in ports, Emission inventory, On-board measurement, Experimental ranking of inventory procedures, Additive value functions.

Corresponding author: Sanaz Jahangiri

E-mail: Sanaz.jahangiri@utas.edu.au 


\section{Introduction}

\subsection{Sea transport and its environmental sustainability}

Transportation of freight and unrefined oil by ships is a critical operation in the transit of petroleum from the Middle East to global users (Michaelowa, 2000), and sea transport is currently recognized as the best method of transport (Wang, Corbett, \& Firestone, 2008). Marine transportation of petroleum and other goods is economical, and ships can transport bulky goods better than other means of transport (Deniz \& Kilic, 2010). Furthermore, sea transport is considered secure (Martínez de Osés \& La Castells, 2010) and improves environmental sustainability as it produces fewer pollutants than land transport (OECD, 1997). The rising popularity of shipping is also expected to increase the number of oceangoing vessels (UNCTAD, 2014).

Even though sea transport is less polluting than land transport, the growing number of shipping activities means that pollution from ships is a significant danger to health. The growing number of shipping activities causes increased pollution levels both globally and in the ports because most shipping companies use low-quality fuel (Deniz \& Kilic, 2010). Therefore, tracing all emissions and determining their possible effects on the environment is a growing necessity. While there is strict regulation and close monitoring of land-related emissions, the sea transport sector lacks adequate mechanisms to monitor and determine the rate of emissions, hindering steps to foster environmental protection and sustainability (Corbett \& Fischbeck, 1997; Corbett et al., 2007).

\subsection{State-of-the-art in emission monitoring for maritime transport}

Shipping operations emit a significant amount of primary emissions including nitrogen oxides $\left(\mathrm{NO}_{2}, \mathrm{NO}, \mathrm{N}_{2} \mathrm{O}\right.$ denoted as a whole with $\left.\mathrm{NO}_{\mathrm{x}}\right)$, sulphur oxides $\left(\mathrm{SO}_{2}, \mathrm{SO}_{3}\right.$, $\mathrm{SO}$ denoted as a whole with $\left.\mathrm{SO}_{\mathrm{x}}\right)$, carbon dioxide $\left(\mathrm{CO}_{2}\right)$, carbon monoxide (CO), volatile organic compounds, in particular hydrocarbon (HC), and particulate matter (PM) (Eyring, Kohler, Van Aardenne, \& Lauer, 2005). Studies have noted that such emissions have adverse consequences on human health and the environment (Corbett et al., 2007; Goldsworthy \& Goldsworthy, 2015). For instance, $\mathrm{NO}_{2}$ and $\mathrm{CO}$ emissions cause flu-like symptoms, while $\mathrm{SO}_{\mathrm{x}}$-pollutants lead to breathing difficulties and PM emissions result in premature deaths (EPA, 2010). Various empirical studies have linked asthma and cardiovascular illnesses to some of those pollutants (Kim, Hwang, \& Lee, 2010; Lu et al., 2006), and some researchers and scientists (Corbett et al., 2007) have reported lung cancer deaths and heart-related diseases connected to PM pollutants in ports in Europe, East Asia and South Asia. Shipping emissions pose various public health consequences for people living near ports, and finding solutions to the situation and taking practical steps to identify and measure emissions precisely require that better procedures and plans to control pollutants need to be developed.

Several studies (Kilic \& Deniz, 2010; Moreno-Gutierrez et al., 2015; Merk, 2014) have considered emissions caused by shipping operations and their effects on distinct scales, such as different seaports and nations. There are some estimates that ocean-going vessels generate $17-31 \%$ of worldwide emissions of $\mathrm{NO}_{\mathrm{x}}$, and $4-10 \%$ of $\mathrm{SO}_{\mathrm{x}}$ (Eyring et al., 2005; Kilic \& Deniz, 2010; Moreno-Gutierrez et al., 2015). A recent study (Merk, 2014) assessed that $\mathrm{CO}_{2}$ from shipping emissions as accounting for approximately 2-3\% of world emissions, which is higher than the amount of non-greenhouse emissions. As the operations of the global fleet of ocean-going vessels increase, emissions are expected to also increase. It is argued in (Eyring et al., 2005) that by the year 2050 the number of vessels will triple, the primary emissions will quadruple, and the emission of $\mathrm{CO}_{2}$ may rise by $50 \%$ of current emissions (Radischat et al., 2015). Approximating and assessing potential amount of and danger caused by shipping emissions is an increasing concern.

Several approaches to estimating shipping emissions have been developed. One such solution is online computer-based monitoring of shipping pollution, which utilizes measurement system as part of the fixed ship equipment. Online monitoring mechanisms provide data over an extended period, but it is very expensive to obtain and maintain because of the aggressive ship environment and the lack of expertise on-board. On top, the measurement results are with low precision and sometimes unreliable (Radischat et al., 2015). Another method is the ship plumes-related measurement, where the measurement equipment is portable and owned by different party. The on-board measurement is conducted on a specified ship whenever it is demanded by the ship owner or by the authorities. The mechanism provides an exact emissions information of a specific vessel. Multiple previously conducted studies applied on-board measurement (Cooper \& Andreasson, 1999; Endresen et al., 2003; Petzold et al., 2006; Sinha et al., 2003). Petzold et al. (2008) focused on a 4-stroke marine engine, while in (Kasper, 
Aufdenblatten, Forss, Mohr, \& Burtscher, 2007) the PM emissions of a 2-stroke marine engine were investigated. Corbett \& Koehler (2003) focused on various pollutants in several types of engine. Others (Cooper, 2001, 2003; Cooper, Peterson, \& Simpson, 1996) evaluated the emissions from the main engines (ME)s and auxiliary engines (AE)s of ferries. Some studies (Kasper et al., 2007; Lyyranen, Jokiniemi, Kauppinen, \& Joutsensaari, 1999; Petzold et al., 2008; Wright, 1997) considered slow speed diesel (SSD) and medium speed diesel (MSD) engines on test rigs. This research focuses on the measurement of emission rates related to marine diesel engines during different stages of operation, both at mooring and while cruising, to provide insights into the emissions produced under different sailing conditions.

Because the utilization of inbuilt measurements proves to be difficult, time-consuming and resourcedemanding, it is difficult to convince ship-owners to purchase and install recommended measurement devices (Cappa et al., 2014; Chen et al., 2005). Therefore, emission inventories are utilized, which are mathematical models to estimate emissions discharged into the atmosphere (Dalsoren et al., 2009; Endresen, Sorgard, Behrens, Brett, \& Isaksen, 2007; Skjølsvik, Andersen, Corbett, \& Skjelvik, 2000). We will be analyzing such emission inventories made during shipping operations. Several factors are taken into account when developing emission inventories, such as the type of fuels, the place to conduct the study, the nature of the vessel, the engine models, etc. Most existing emission inventories are affected by weak quantifications and application of traditional emission elements to measure both regional and global air quality, such as US EPA discussed in (Browning \& Bailey, 2006).

Various methodologies exist that can utilize shipping emission inventories as a way to make accurate estimations of the level of emissions from shipping. The thirteen methods used in this study are: Tier I-III (Trozzi \& De Lauretis, 2013), ENTEC (ENTEC. 2007), MEET (Hickman, Hassel, Joumard, Samaraz \& Sorensen, 1999), STEAM (Jalkanen et al., 2009), MOPSEA (Gommers, Verbeeck, Cleemput, Schrooten \& De Vlieger, 2007), IMO (IMO. 2014), SMED (Cooper \& Gustafsson, 2004), EMS (Van der Gon \& Hulskotte, 2010), US EPA (Hockstad \& Hanel, 2018), NERI (Olesen, Winther, Ellermann, Christensen, \& Plejdrup, 2009) and Corbett (Corbett et al., 2003). These approaches can be categorized into three groups: a full bottom-up approach, a comprehensive top-down approach, and a mixed approach, as postulated by Miola and Ciuffo (2011). The categorization is according to the emissions evaluation and the geographical characterization.

A full bottom-up approach assesses the levels and types of emissions generated by a single ship, considering the nature of the vessel, which includes ship type, date of construction, quality of engine and the specific fuel oil consumption (SFOC) at a given point (Moreno-Gutierrez et al., 2015). This allows the underlying factors of the emissions to be identified and evaluated, leading to an explicit understanding of the consequences they may have. ENTEC, Corbett, STEAM, MOPSEA, NERI, EMS, US EPA, and SMED belong to this category in our study.

An entirely top-down methodology observes emissions from a more global perspective and utilizes generalized factors, such as fuel consumption data for given fuel types and the types of engines used in particular ships as determinants of emissions (Miola \& Ciuffo, 2011).

Some of the methods discussed in this paper follow a mixed approach. Tier I-III displays some top-down characteristics regarding emission inventories, but tends to be bottom-up regarding geographical distribution. The MEET and IMO approximate a bottom-up emissions inventory and a top-down geographic distribution.

Whichever approach is adopted, each inventory method predicts a set of emission factors (EF)s that will deviate from the experimental measurement values. The main reason for the observed discrepancies between the observed and predicted EFs is that most of the inventories are developed under specific assumptions that include fuel type, consumption units of fuel, ship navigation locations, types of ships, the nature of engines, type of the vessels, etc., which in any particular case will be different from the actual one. It is therefore important to determine a good-enough emission inventory mechanism that is premised on the factors and assumptions which are as close as possible to the actual factors and assumptions for the vessel whose EFs are to be predicted.

\subsection{Objectives of the study}

The first objective of this paper is to present a comprehensive case study to identify the best vessel-specific inventory family predicting the primary emissions from ocean-going vessels when at berth, while maneuvering and while cruising. In the case study, the primary emission rates of $\mathrm{NO}_{x}, \mathrm{SO}_{x}, \mathrm{CO}_{2}, \mathrm{CO}, \mathrm{HC}$, and PM were measured during on-board experimental measurement campaign for the three modes of the vessel's operation. The emissions were predicted with 13 families of emission inventories (Tier I-III, ENTEC, MEET, STEAM, MOPSEA, IMO, SMED, EMS, US EPA, NERI and Corbett) and prediction deviations have been calculated. 
Another objective is to create generalized rational algorithm to rank inventory families based on the precision of their predictions for a given operational mode of a specific vessel.

The third objective is to use the implications of the case study together with the developed algorithm to rank inventory families to offer a novel future policy for a cost-effective and reliable emission estimation caused by shipping.

In what follows, section 2 explains the conditions and the procedures in the on-board measurement campaign. The results of the comparison analysis between the measured and predicted emissions are described in section 3 . In section 4, a six-attribute value function is discussed as a rational alternative for the minimal mean absolute deviation criterion and general algorithm for identifying the best vessel-specific inventory families for a given mode of operation. Based on the case study implications, a possible future policy for ship emission evaluation is advised. Section 5 concludes the paper.

\section{On-board campaign measurement}

\subsection{General description of on-board measurements campaign}

Measurements were taken on-board a large hauler ship as it approached Newcastle from Gladstone, Australia. This vessel, manufactured in 2002, is $187.5 \mathrm{~m}$ in length, with a 27198 GRT capacity and an average steaming speed of 11.6 knots. The vessel has a MAN B\&W 6S50MC main engine, which is $6880-\mathrm{kW}$, two-stroke, six-cylinder, slow speed diesel (SSD). Each of the auxiliary engines is Wartsila 20, which is $460-\mathrm{kW}$, four-stroke, four-cylinder, medium speed diesel (MSD).

Measurements of emissions were taken on-board following the procedures elaborated in ISO 8178-2:2008 (Jalkanen et al., 2012) and ISO 8178-1:2006 (MEET, 1999). The on-board emission measurement campaign was divided into 4 separate experiments. The first one was to measure the $\mathrm{NO}_{\mathrm{x}}, \mathrm{SO}_{\mathrm{x}}, \mathrm{CO}_{2}$, and $\mathrm{CO}$ emissions from the $\mathrm{AE}$ when the vessel was at berth. The second, third, and fourth experiment were to measure the $\mathrm{NO}_{\mathrm{x}}, \mathrm{SO}_{\mathrm{x}}, \mathrm{CO}_{2}, \mathrm{CO}$, $\mathrm{HC}$, and PM emissions from the ME when the vessel was at berth, maneuvering, and cruising respectively.

For the main engine experiments the probes of the exhaust gas were sampled between the turbocharger and the economizer of the ME. The emission rates of $\mathrm{SO}_{x}, \mathrm{CO}_{2}, \mathrm{CO}$, and $\mathrm{HC}$ were measured with main gas analyzer Testo $350 \mathrm{XL}$. The emission rates $\mathrm{HC}$ were measured with Horiba MEXA 584L 5-gas analyzer. The mass concentration of PM was measured with Dust Trak Aerosol Monitor 8530 (TSI) separately for $\mathrm{PM}_{2.5-10}$ (with aerodynamic diameters between 2.5 and $10 \mu \mathrm{m}$ ), $\mathrm{PM}_{1.0-2.5}$ (with aerodynamic diameters between 1.0 and $2.5 \mu \mathrm{m}$ ), and $\mathrm{PM}_{1.0}$ (with aerodynamic diameters less than $1.0 \mu \mathrm{m}$ ). To cool the probe for PM measurement, the sample was diluted with air. The rates of the samples' dilution were estimated by comparing the $\mathrm{CO}_{2}$ emission rate in the initial sample with, the $\mathrm{CO}_{2}$ emission rate of the diluted sample measured with Sable CA-10 $\mathrm{CO}_{2}$ monitor. Simultaneously the shaft speed (SS) and the actual engine power ( $\mathrm{Pact}$ ) were measured every $5 \mathrm{sec}$. The specific oil consumption (SOC) was determined as a quadratic function of the engine load factor LF (the actual engine power measured in $\%$ of the maximum continues rating of the engine). The average air consumption (AC) was assessed as a linear function of the load factor. The instantaneous exhaust mass flow rate (EMFR) was assessed as the sum of AC with the product of SOC and Pact.

For the auxiliary engine experiments, the probes of the exhaust gas were sampled after the turbocharger. The measurement equipment was Testo $350 \mathrm{XL}$ only. In this experiment, HC and PM were not measured. The SS, Pact, SOC, AC and EMFR were obtained as in the ME experiments.

For each of the experiments the probes were taken at equal inter-sample interval $\Delta t$. If the duration of the experiment is $T$, then the count of the probes sampled for measurement is $N=T / \Delta t$. The time when the $i$-th probe was sampled is $t_{i}=(i-0.5) \Delta t$ for $i=1,2, \ldots, N$. The parameters of the measurement process for each of the experiments are given in Table 1. 


\begin{tabular}{|c|c|c|c|c|}
\hline Experiment & $\begin{array}{c}\text { Inter-sample } \\
\text { Interval (h) }\end{array}$ & $\begin{array}{l}\text { Count of } \\
\text { Samples }\end{array}$ & $\begin{array}{l}\text { Duration } \\
\text { (h) }\end{array}$ & $\begin{array}{l}\text { Duration } \\
(h, \text { min, s) }\end{array}$ \\
\hline$\overline{\mathrm{ME}}$ at berth for $\mathrm{NO}_{\mathrm{x}}$ & $1 / 3600$ & 1569 & 0.4358 & $26 \mathrm{~min}, 9 \mathrm{~s}$ \\
\hline $\mathrm{ME}$ at berth for $\mathrm{SO}_{\mathrm{x}}, \mathrm{CO}$ & $1 / 3600$ & 1577 & 0.4381 & $26 \mathrm{~min}, 17 \mathrm{~s}$ \\
\hline $\mathrm{ME}$ at berth for $\mathrm{CO}_{2}$ & $1 / 3600$ & 1521 & 0.4225 & $25 \mathrm{~min}, 22 \mathrm{~s}$ \\
\hline $\mathrm{ME}$ at berth for $\mathrm{HC}$ & $300 / 3600$ & 4 & 0.3333 & $20 \mathrm{~min}$ \\
\hline ME at berth for PM & $300 / 3600$ & 5 & 0.4167 & $25 \mathrm{~min}$ \\
\hline $\mathrm{AE}$ at berth for $\mathrm{NOx}, \mathrm{SO}_{\mathrm{x}}, \mathrm{CO}_{2}, \mathrm{CO}$ & $1 / 3600$ & 9476 & 2.632 & $2 \mathrm{~h}, 37 \mathrm{~min}, 56 \mathrm{~s}$ \\
\hline ME maneuvering for $\mathrm{NO}_{\mathrm{x}}$ & $1 / 3600$ & 6553 & 1.820 & $1 \mathrm{~h}, 49 \mathrm{~min}, 13 \mathrm{~s}$ \\
\hline ME maneuvering for $\mathrm{SO}_{\mathrm{x}}$ & $1 / 3600$ & 6558 & 1.822 & $1 \mathrm{~h}, 49 \mathrm{~min}, 18 \mathrm{~s}$ \\
\hline ME maneuvering for $\mathrm{CO}_{2}$ & $1 / 3600$ & 6522 & 1.812 & $1 \mathrm{~h}, 48 \mathrm{~min}, 42 \mathrm{~s}$ \\
\hline ME maneuvering for $\mathrm{CO}$ & $1 / 3600$ & 6542 & 1.817 & $1 \mathrm{~h}, 49 \min , 2 \mathrm{~s}$ \\
\hline ME maneuvering for $\mathrm{HC}$ & $300 / 3600$ & 5 & 0.4167 & $25 \min$ \\
\hline ME maneuvering for PM & $300 / 3600$ & 27 & 2.250 & $2 \mathrm{~h}, 15 \mathrm{~min}$ \\
\hline ME cruising for $\mathrm{NO}_{x}, \mathrm{SO}_{x}, \mathrm{CO}_{2}, \mathrm{CO}$ & $1 / 3600$ & 15305 & 4.251 & $4 \mathrm{~h}, 15 \mathrm{~min}, 5 \mathrm{~s}$ \\
\hline ME cruising for $\mathrm{HC}, \mathrm{PM}$ & $300 / 3600$ & 64 & 5.333 & $5 \mathrm{~h}, 20 \mathrm{~min}$ \\
\hline
\end{tabular}

\subsection{On-board measurements}

For the five gases $\left(\mathrm{NO}_{\mathrm{x}}, \mathrm{SO}_{\mathrm{x}}, \mathrm{CO}_{2}, \mathrm{CO}\right.$, and $\left.\mathrm{HC}\right)$ the measured instantaneous emission rates at time $t_{i}$ were converted into instantaneous emission factors (EFs) using the atmospheric pressure, the exhaust gas temperature, the exhaust flow rate (which is the total fuel and air consumption divided by the mass density of the exhaust gas), the molar mass of the gas, the air density, and the engine power. The later was linearly interpolated for each $t_{i}$ from the measured engine power data. For each of the three types of PM (PM2.5-10, PM1.0-2.5, and PM1.0) the mass concentrations were converted into instantaneous emission factors (EFs) using the exhaust flow rate, the dilution rate (calculated from the difference of the $\mathrm{CO}_{2}$ measured before and after the dilution of the hot probe with cold air), the air density, and the actual engine power ( $\left.\mathrm{P}_{\mathrm{act}}\right)$. The EF of the PM is calculated as the sum of the EFs for $\mathrm{PM}_{2.5-10}, \mathrm{PM}_{1.0-2.5}$, and $\mathrm{PM}_{1.0}$. When not measured, the EF for $\mathrm{PM}_{2.5-10}$ is assessed as $20 \%$ of the EF of PM (Hockstad \& Hanel, 2018). In the same way when not measured, the EFs for $\mathrm{PM}_{1.0-2.5}$, and $\mathrm{PM}_{1.0}$ are substituted with the mean of the respective measured EFs. The micro emission in the interval $\Delta t$ centered around time $t_{i}$ was calculated as the instantaneous emission factor multiplied by $\mathrm{P}_{\text {act }}$ and by $\Delta t$. The total emission during any experiment was estimated as sum of the micro emissions measured. The measured average emission factors given in Tables 2 were calculated as the total emissions divided by the product of the average engine power with the experimental time $T$. The average shaft speed, the average actual power of the engine, the average load factor, the average air consumption, and the average exhaust mass flow rate for each of the experiments are also given in Table 2.

\begin{tabular}{|c|c|c|c|c|c|c|c|c|c|c|c|c|}
\hline \multirow[t]{2}{*}{ Experiment } & \multirow{2}{*}{$\begin{array}{l}\text { Ave. } \\
\text { SS } \\
\text { (rpm) }\end{array}$} & \multirow{2}{*}{$\begin{array}{c}\text { Ave. } \\
\text { Pact } \\
(\mathrm{kW})\end{array}$} & \multirow{2}{*}{$\begin{array}{l}\text { Ave. } \\
\text { LF } \\
(\%)\end{array}$} & \multirow{2}{*}{$\begin{array}{c}\text { Ave. } \\
\text { AC } \\
(\mathrm{kg} / \mathrm{h})\end{array}$} & \multirow{2}{*}{$\begin{array}{c}\text { Ave. } \\
\text { EMFR } \\
(\mathrm{kg} / \mathrm{h})\end{array}$} & \multirow{2}{*}{$\begin{array}{l}\text { Ave. SOC } \\
\text { (g/kWh) }\end{array}$} & \multicolumn{6}{|c|}{ Average Measured Emission Factors in (g/kWh) } \\
\hline & & & & & & & $\mathrm{NO}_{\mathrm{x}}$ & $\mathrm{SO}_{\mathrm{x}}$ & $\mathrm{CO}_{2}$ & $\mathrm{CO}$ & $\mathrm{HC}$ & $\mathrm{PM}$ \\
\hline ME at berth for $\mathrm{NO}_{\mathrm{x}}$ & 38.11 & 509.0 & 7.399 & 5860 & 5990 & 256.6 & 10.1 & & & & & \\
\hline $\mathrm{ME}$ at berth for $\mathrm{SO}_{\mathrm{x}}, \mathrm{CO}$ & 38.15 & 510.5 & 7.421 & 5877 & 6008 & 256.5 & & 9.10 & & 1.48 & & \\
\hline $\mathrm{ME}$ at berth for $\mathrm{CO}_{2}$ & 38.25 & 507.5 & 7.376 & 5842 & 5972 & 256.6 & & & 476 & & & \\
\hline $\mathrm{ME}$ at berth for $\mathrm{HC}$ & 36.62 & 451.5 & 6.563 & 5197 & 5313 & 257.7 & & & & & 0.400 & \\
\hline ME at berth for PM & 39.8 & 578.2 & 8.404 & 6656 & 6804 & 255.2 & & & & & & 2.23 \\
\hline $\begin{array}{l}\mathrm{AE} \text { at berth for } \mathrm{NO}_{\mathrm{x}}, \mathrm{SO}_{\mathrm{x}} \\
\mathrm{CO}_{2}, \mathrm{CO}\end{array}$ & 900.0 & 265.0 & 57.61 & 2862 & 2930 & 256.0 & 11.2 & 26.2 & 1140 & 1.74 & & \\
\hline ME maneuvering for $\mathrm{NO}_{\mathrm{x}}$ & 65.31 & 2444 & 35.53 & 28140 & 28690 & 226.4 & 11.5 & & & & & \\
\hline ME maneuvering for $\mathrm{SO}_{\mathrm{x}}$ & 65.30 & 2442 & 35.51 & 28120 & 28670 & 226.4 & & 13.8 & & & & \\
\hline $\mathrm{ME}$ maneuvering for $\mathrm{CO}_{2}$ & 65.45 & 2453 & 35.65 & 28240 & 28790 & 226.3 & & & 687 & & & \\
\hline ME maneuvering for $\mathrm{CO}$ & 65.29 & 2443 & 35.50 & 28120 & 28670 & 226.4 & & & & 2.43 & & \\
\hline ME maneuvering for $\mathrm{HC}$ & 80.94 & 3785 & 55.01 & 43570 & 44380 & 214.3 & & & & & 0.239 & \\
\hline ME maneuvering for PM & 67.84 & 2653 & 38.56 & 30540 & 31130 & 224.0 & & & & & & 1.70 \\
\hline $\begin{array}{l}\mathrm{ME} \text { cruising for } \mathrm{NO}_{\mathrm{x}}, \mathrm{SO}_{\mathrm{x}} \\
\mathrm{CO}_{2}, \mathrm{CO}\end{array}$ & 89.50 & 5595 & 81.33 & 64410 & 65560 & 205.5 & 19.0 & 18.1 & 764 & 1.12 & & \\
\hline ME cruising for $\mathrm{HC}, \mathrm{PM}$ & 89.26 & 5663 & 82.31 & 65190 & 66340 & 203.1 & & & & & 0.146 & 0.391 \\
\hline
\end{tabular}


While at berth, the AEs run to generate the required auxiliary power (Hickman et al., 1999) and can be said to be the key emission producer (Du et al., 2011). Major activities include, but are not limited to, light supply to the ship, refrigeration, heating, ventilation, and electric equipment electric loads (Hickman et al., 1999). The AEs operate with greater load factor (LF) than ME and therefore produce higher EFs (Table 2).

The main engine runs on heavy fuel oil (HFO) with 3.13\% sulphur mass content that was adopted for the fuel type in this study. HFO is a fuel type preferred for most ship's boilers and engines (Goldsworthy \& Galbally, 2011), with a sulphur content ranging from $2 \%$ to $3.5 \%$ with a $2.6 \%$ average globally (IMO, 2010). The properties of the HFO used in our study are given in Table 3. For most ships sailing to Australia, the average fuel sulphur content of the HFO may be higher than this average (Goldsworthy \& Goldsworthy, 2015). Also, HFO combustion is very complex and may emit primary gases (Goldsworthy \& Galbally, 2011).

\section{Table 3: Properties of the heavy fuel oil used}

Density at $15^{\circ} \mathrm{C}$

Viscosity at $50^{\circ} \mathrm{C}$

Micro - carbon residue

Sulphur (S)

Ash

Vanadium (V)

\author{
$986 \mathrm{~kg} / \mathrm{m}^{3}$ \\ $377 \mathrm{~mm}^{2} / \mathrm{s}$ \\ $14.6 \%$ mass \\ $3.13 \%$ mass \\ $0.0640 \%$ mass \\ $141 \mathrm{mg} / \mathrm{kg}$
}

Since $\mathrm{NO}_{\mathrm{x}}$ and $\mathrm{CO}$ emissions are combustion dependent, service history and individual maintenance are a concern (Cooper, 2003). Higher amounts of nitrogen in fuels can produce $\mathrm{NO}_{\mathrm{x}}$ emissions (Cooper, 2003). For this study, nitrogen content was $0.68 \%$ of the total mass. Thermally, greater nitrogen fixation during combustion is required if temperature periods are long and the engine is slow. The level of PM in marine diesel emissions may vary with fuel type or combustion conditions and more will be generated by higher amounts of fuel sulphur plus ash content. Dependency on PM fuel emissions becomes less conspicuous compared to $\mathrm{CO}_{2}$ and $\mathrm{SO}_{2}$ emissions due to induced PM combustion emissions (Cooper, 2003). According to Agrawal et al. (2008), the higher the quantity of ash content, the higher the PM EFs, although, in a general sense, there is insufficient data on the measurement of PM and differences in engine models, fuel used, instrumentations and working conditions (Hallquist, Fridell, Westerlund, \& Hallquist, 2013).

Variations in engine power and speed may result in poor combustion, which can lead to increased HC and PM emission rates. PM concentration is largely dependent on the conditions of engine load, which is higher at low LFs and vice-versa (Winnes \& Fridell, 2009): if the average power is considered with LFs remaining at their lowest in berth, the EF results for $\mathrm{PM}$ produce greater amounts. However, $\mathrm{EF}$ averages for $\mathrm{NO}_{\mathrm{x}}, \mathrm{CO}_{2}$ and $\mathrm{SO}_{\mathrm{x}}$ in cruising mode are higher than when maneuvering at berth. All $\mathrm{NO}_{\mathrm{x}}$ emissions are temperature dependent, increasing with a rise in temperature. Hence, the rate of emission of $\mathrm{NO}_{\mathrm{x}}$ is dependent on a ship's engine power and engine $\mathrm{LF}$ (Sinha et al., 2003). If the engine is steady, with a speed higher than its power, while in operation it may run for longer and at higher temperatures, producing higher $\mathrm{NO}_{\mathrm{x}}$ emissions. Pollution rates, then, increase with increased engine power. The demand of engine power, air consumption and mass flow of exhaust emissions increase during cruising. Moreover, an elevated engine load increases the average engine power, which in turn additionally increases the influence of the fuel's carbon and sulphur content (Table 3) on the $\mathrm{EFs}$ of $\mathrm{SO}_{\mathrm{x}}$ and $\mathrm{CO}_{2}$ for $\mathrm{cruising}$ modes compared with other operating modes (Table 2). Generally, the $\mathrm{CO}$ emissions recorded were low, a result of high oxygen surplus concentrations and an adequate combustion process, but if engines are poorly maintained at small power ranges, $\mathrm{CO}$ proportions may increase expectedly due to considerable relative concentration (Kristensen, 2010). In this study, generally the EFs for CO are low but they increase at the maneuvering phase. Variable engine speed and power may lead to poor combustion during the maneuvering phase leading to increased CO emission rates (Fu et al., 2013).

\section{Comparison analysis between measured and predicted EFs}

In this section the on-board experimental measurements are compared with the predictions of the inventory methods introduced in section 1.2. As described in section 2.1 the primary emission rates (or the mass concentration for PM) of the main engine were measured at berth, while maneuvering, and while cruising. For the auxiliary engines the only rates measured were $\mathrm{NO}_{x}, \mathrm{SO}_{x}, \mathrm{CO}_{2}$ and $\mathrm{CO}$ emissions at berth. In section 2.2 , the 
measured emission rates were converted to EFs and the results were shown in Table 2. The total emission amount of given type released in the atmosphere during one experiment (e.g. $\mathrm{CO}$ emission of the ME during the maneuvering experiment) can be calculated by integrating the time curve of the instantaneous emissions for the time span of the experiment (e.g. $1 \mathrm{~h}, 49 \mathrm{~min}, 2 \mathrm{sec}$ for $\mathrm{CO}$ emission of the ME during the maneuvering). The instantaneous emission in $\mathrm{g} / \mathrm{h}$ at time $t$ is the $\mathrm{EF}$ at time $t$, multiplied by the actual engine power at time $t$. The total emission amount measured for each "pollutant" (inclusive of $\mathrm{CO}_{2}$, which technically is not a pollutant) from the four experiment types are given in $\mathrm{kg}$ on the first row of Tables 4, 5, 7, and 8. For each total emission amount measured, we have tried to predict the results with as many inventories as possible from the list of inventories given in Section 1.2. Each of the inventories is predicting the EF generally as a function of the load factor, the type of the fuel, the sulphur content of the fuel, the type of the engine, the operation mode, the built date of the engine, the shaft rotational speed, specific fuel consumption, etc. The inventory-predicted emission factor for any emission has been converted into inventory-predicted total emission amount by multiplying with the average engine power and the experiment time $T$. We opted to calculate the total predicted emissions in that simplified way instead of integrating the instantaneous emission curves in order to mimic more closely the real utilization of the inventory prediction. The inventory deviations of the predicted total emission amount in \% from the experimentally measured total emission amounts can be calculated for all "pollutants" (note that $\mathrm{CO}_{2}$ is not a pollutant), and for any inventory method that can predict that pollutant. Those inventory deviations from the four experiment types are given in Tables 4, 5, 7, and 8 (from the second row onward, excluding the last columns of Tables 7 and 8).

Example 1: MEET inventory prediction for $\mathrm{CO}$ emission of the auxiliary engine is

$$
\mathrm{EF}_{\mathrm{CO}}^{\mathrm{MEET}}=\left[20.7-0.218(\mathrm{LF})-0.0231 \mathrm{P}_{\text {act }}+0.000345 \mathrm{P}_{\text {act }}(\mathrm{LF})\right] \mathrm{SOC} / 1000
$$

For the auxiliary engine at berth the average load factor $\mathrm{LF}$ is $57.6 \%$, the average engine power $\mathrm{P}_{\text {act }}$ is $265 \mathrm{~kW}$, the average specific oil consumption SOC is $256 \mathrm{~g} / \mathrm{kWh}$ (see Table 2). So,

$$
\mathrm{EF}_{\mathrm{CO}}^{\mathrm{MEET}}=[20.7-0.218(57.6)-0.0231(265)+0.000345(265)(57.6)](256.0) / 1000 \approx 1.87 \mathrm{~g} / \mathrm{kWh}
$$

For $\mathrm{CO}$ emission from the auxiliary engine at berth the experimental time is $2.632 \mathrm{~h}$ (see Table 1). The MEET predicted total $\mathrm{CO}$ emission amount is

$$
\mathrm{CO}^{\mathrm{MEET}}=\mathrm{EF}_{\mathrm{CO}}^{\mathrm{MEET}} \mathrm{P}_{\text {act }} T=1.87(265)(2.632) / 1000 \approx 1.304 \mathrm{~kg}
$$

The MEET inventory deviation in \% from $1.214 \mathrm{~kg}$, which is the experimentally measured total CO emission amount for the auxiliary engine at berth (see Table 5) is

$$
\Delta \mathrm{CO}^{\mathrm{MEET}}=100\left(\mathrm{CO}^{\mathrm{MEET}}-\mathrm{CO}^{\mathrm{mes}}\right) / \mathrm{CO}^{\text {mes }}=100(1.304-1.214) / 1.214 \approx 7.43 \%
$$

That result is shown in Table 5.

Example 2: The ENTEC prediction for the $\mathrm{NO}_{\mathrm{x}}$ emission factor from the main engine when the vessel is maneuvering was $\mathrm{EF}_{\mathrm{NO}_{\mathrm{x}}}^{\mathrm{ENTEC}}=12.0 \mathrm{~g} / \mathrm{kWh}$. The latter value considers that the vessel is at maneuvering, that the main engine is post-2000 SSD, and that the fuel is $\mathrm{HFO}$. For $\mathrm{NO}_{\mathrm{x}}$ emission from the main engine when maneuvering the experimental time is $1.820 \mathrm{~h}$ (see Table 1), and the average engine power $\mathrm{P}_{\text {act }}$ is $2444 \mathrm{~kW}$ (see Table 2). The ENTEC predicted total $\mathrm{NO}_{\mathrm{x}}$ emission amount is,

$$
\mathrm{NO}_{\mathrm{x}}^{\mathrm{ENTEC}}=\mathrm{EF}_{\mathrm{NO}}^{\mathrm{ENTEC}} \mathrm{P}_{\mathrm{act}} T=12.0(2444)(1.820) / 1000 \approx 53.4 \mathrm{~kg}
$$

The ENTEC inventory deviation in \% from $51.17 \mathrm{~kg}$, which is the experimentally measured total $\mathrm{NO}_{\mathrm{x}}$ emission amount for the main engine at maneuvering (see Table 7) is,

$$
\Delta \mathrm{NO}_{\mathrm{x}}^{\mathrm{ENTEC}}=100\left(\mathrm{NO}_{\mathrm{x}}^{\mathrm{ENTEC}}-\mathrm{NO}_{\mathrm{x}}^{\text {mes }}\right) / \mathrm{NO}_{\mathrm{x}}^{\text {mes }}=100(53.4-51.17) / 51.17 \approx 4.33 \%
$$

That result is shown in Table 7.

Example 3: US EPA inventory prediction for $\mathrm{SO}_{\mathrm{x}}$ emission of the main engine is

$$
\mathrm{EF}_{\mathrm{SO}_{x}}^{\mathrm{US} \mathrm{EPA}}=2.3735(\mathrm{SOC})(\mathrm{FSF})-0.4792
$$

For $\mathrm{SO}_{\mathrm{x}}$ emission of the main engine at berth the specific oil consumption $\mathrm{SOC}=256.5 \mathrm{~g} / \mathrm{kWh}$ (see Table 2), and the fuel sulphur fraction in the HFO is FSF $=0.0313$ (see Table 3). So,

$$
\mathrm{EF}_{\mathrm{SO}_{x}}^{\mathrm{US} \mathrm{EPA}}=2.3735(256.5)(0.0313)-0.4792 \approx 18.54 \mathrm{~g} / \mathrm{kWh}
$$


For $\mathrm{SO}_{\mathrm{x}}$ emission of the main engine the experimental time $T$ is $0.4381 \mathrm{~h}$ (see Table 1 ), and the average engine power $\mathrm{P}_{\text {act }}$ is $510.5 \mathrm{~kW}$ (see Table 1). The US EPA predicted total $\mathrm{SO}_{\mathrm{x}}$ emission amount is,

$$
\mathrm{SO}_{\mathrm{x}}^{\mathrm{USEPA}}=\mathrm{EF}_{\mathrm{SO}_{\mathrm{x}}}^{\mathrm{US} \mathrm{EPA}} \mathrm{P}_{\mathrm{act}} T=18.54(510.5)(0.4381) / 1000 \approx 4.147 \mathrm{~kg}
$$

The US EPA inventory deviation in \% from $2.035 \mathrm{~kg}$, which is the experimentally measured $\mathrm{SO}_{\mathrm{x}}$ emission amount for the main engine at berth (see Table 4) is,

$$
\Delta \mathrm{SO}_{\mathrm{x}}^{\mathrm{US} E P A}=100\left(\mathrm{SO}_{\mathrm{x}}^{\mathrm{US} E P A}-\mathrm{SO}_{\mathrm{x}}^{\text {mes }}\right) / \mathrm{SO}_{\mathrm{x}}^{\text {mes }}=100(4.147-2.035) / 2.035 \approx 104 \%
$$

That result is shown in Table 4.

\subsection{Inventories Performance when the Vessel is at Berth}

The experimentally measured total emission amounts and the inventory predictions for the main engine at berth are shown in Figure 1. The experimentally measured total emission amounts and the inventory deviations in $\%$ from the experimental values for the main engine at berth are given in Table 4.

Most methods systemically over-predict the on-board measured total emission amounts of $\mathrm{NO}_{\mathrm{x}}, \mathrm{CO}_{2}$, $\mathrm{CO}$, and $\mathrm{HC}$ from the main engine at berth. The $\mathrm{SO}_{\mathrm{x}}$ inventories' predictions are well scattered around the measured total emission amounts. The PM inventories' predictions are somewhat scattered around the measured total emission amount, although some under-prediction is obvious. The inventory predictions for $\mathrm{NO}_{x}, \mathrm{CO}_{2}$, and $\mathrm{PM}$ are somewhat satisfactory because the absolute deviations does not exceed $68.8 \%, 72.6 \%$, and $86.3 \%$ respectively. However, the inventory predictions for $\mathrm{SO}_{\mathrm{x}} \mathrm{CO}$, and $\mathrm{HC}$ are completely unreliable with maximal absolute deviations reaching

\begin{tabular}{|c|c|c|c|c|c|c|}
\hline Inventory & NO $_{x}$ & SO $_{x}$ & $\mathrm{CO}_{2}$ & $\mathrm{CO}$ & HC & PM \\
\hline Experiment & 2.248 & 2.035 & 102.0 & 0.3319 & 0.06022 & 0.5373 \\
\hline Tier III & 38.1 & 37.4 & $\mathrm{NaN}$ & -0.276 & 350 & 7.62 \\
\hline ENTEC & 18.4 & 27.5 & 43.4 & $\mathrm{NaN}$ & 350 & 7.62 \\
\hline MEET & -11.4 & 76.9 & 72.6 & 1610 & 1390 & -86.3 \\
\hline STEAM & 114 & -34.2 & 31.0 & $\mathrm{NaN}$ & $\mathrm{NaN}$ & $\mathrm{NaN}$ \\
\hline MOPSEA & 68.8 & -34.1 & 30.8 & 6.46 & -41.0 & -47.5 \\
\hline NERI & 18.4 & -56.0 & 34.1 & 7.81 & 25.0 & -83.9 \\
\hline EMS & 77.7 & 18.7 & 33.5 & 79.2 & 45.0 & -41.7 \\
\hline US EPA & 64.8 & 104 & 162 & 668 & 987 & -77.7 \\
\hline IMO & 64.8 & -49.1 & 21.1 & -65.5 & 42.5 & -39.5 \\
\hline
\end{tabular}
$104 \%, 1610 \%$, and $1390 \%$ respectively.

The inventories, which produce least absolute deviations for the main engine at berth are MEET for $\mathrm{NO}_{\mathrm{x}}$ with $-11.4 \%$ deviation, EMS for $\mathrm{SO}_{\mathrm{x}}$ with $18.7 \%$ deviation, IMO for $\mathrm{CO}_{2}$ with $21.1 \%$ deviation, MOPSEA for CO with $6.46 \%$ deviation, NERI for HC with $25.0 \%$ deviation, and jointly TIER III \& ENTEC for PM with 7.62\% deviation.

The experimentally measured total emission amounts and the inventory predictions for the auxiliary engines at berth are shown in Figure 2. The experimentally measured total emission amounts and the inventory deviations in $\%$ from the experimental values for the auxiliary engines at berth are given in Table 5 .

Most methods systemically over-predict the on-board measured total emission amounts of $\mathrm{NO}_{\mathrm{x}}$, whereas at the same time systemically under-predict the on-board measured total emission amounts of $\mathrm{SO}_{\mathrm{x}}$ and $\mathrm{CO}_{2}$ from the auxiliary engines at berth. The CO inventories' predictions are somewhat scattered around the measured CO total emission amount, although some under-prediction can be detected. The $\mathrm{CO}_{2}$ is more or less well predicted by every inventory method, with absolute deviations less than $45.4 \%$. The inventory predictions for $\mathrm{NO}_{\mathrm{x}}, \mathrm{SO}_{\mathrm{x}}$, and $\mathrm{CO}$ also are somewhat satisfactory because their respective absolute deviations do not exceed 81.8\%, 98.5\%, and 54.0\%. 


\section{Figure 1: Total emission amounts' measurement and inventory prediction at berth for the main engine}
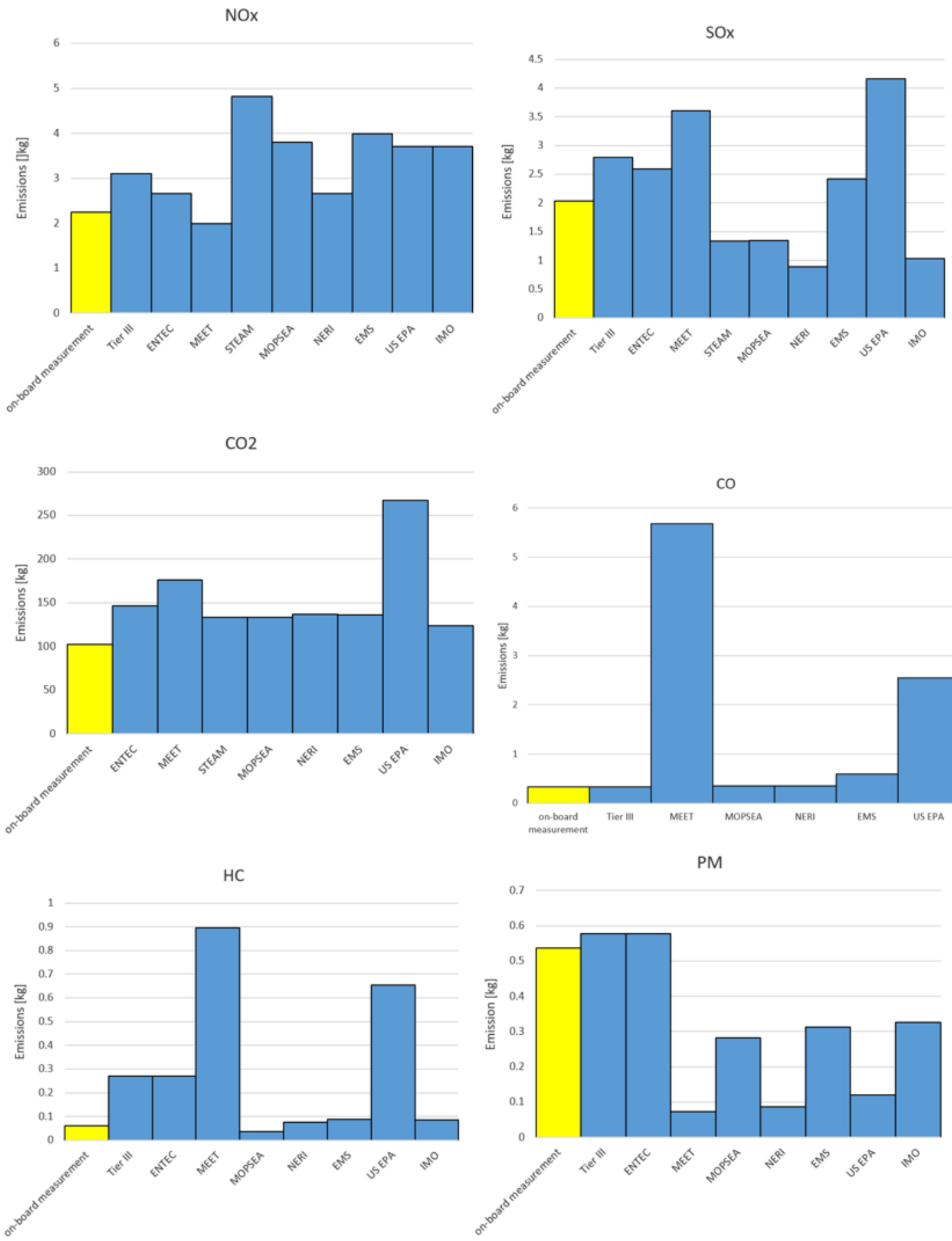

The inventories, which produce least absolute deviations for the auxiliary engines at berth, are MEET for $\mathrm{SO}_{\mathrm{x}}$ and $\mathrm{CO}_{2}$ with $-38.8 \%$, and $-28.2 \%$ deviations respectively, NERI for $\mathrm{NO}_{\mathrm{x}}$ with $-1.50 \%$ deviation, and MOPSEA for CO with $-5.79 \%$ deviation.

The experimentally measured total emission amounts for the main engine and the auxiliary engines at berth were converted to hourly emission amounts, by dividing the former with the respective experimental time in hours. The combined hourly emission amount from all engines at berth has been calculated as the sum of the hourly emission amounts from main engine and from auxiliary engines. The experimentally measured combined hourly emission amounts are given in on the first row of Table 6, except for the HC and PM column where the 
hourly emission amount are from the main engine, only (see section 2.1). The inventory deviation in \% for any hourly emission amount prediction is the same as that of the total emission amount prediction. The combined hourly emission amount prediction can be calculated as the sum of two independent hourly amount predictions: one for the main engine and one for the auxiliary engines. It is trivial to prove that the inventory deviation from the experimentally measured combined hourly emission amount in \% is a weighted average of the two inventory deviations from total emission amounts in \% (one for the main engine and one for the auxiliary engines). The weight coefficients are the experimentally measured hourly emission amounts from the main engine and auxiliary engines respectively.

\begin{tabular}{|c|c|c|c|c|}
\hline Inventory & $\mathrm{NO}_{\mathrm{x}}$ & $\mathrm{SO}_{\mathrm{x}}$ & $\mathrm{CO}_{2}$ & $\mathrm{CO}$ \\
\hline Experiment & 7.790 & 18.26 & 795.5 & 1.214 \\
\hline Tier III & 27.1 & -47.3 & $\mathrm{NaN}$ & -6.36 \\
\hline ENTEC & 9.24 & -53.0 & -36.7 & $\mathrm{NaN}$ \\
\hline MEET & 94.3 & -38.9 & -28.2 & 7.43 \\
\hline STEAM & 2.97 & -77.1 & -45.4 & $\mathrm{NaN}$ \\
\hline MOPSEA & -21.2 & -74.8 & -40.0 & -5.79 \\
\hline NERI & -1.50 & -98.5 & -38.4 & -8.08 \\
\hline EMS & 34.3 & -54.5 & -38.8 & 54.0 \\
\hline US EPA & 31.6 & -54.2 & -36.6 & -36.8 \\
\hline SMED & 25.4 & -60.3 & -36.7 & -48.3 \\
\hline IMO & 81.8 & -78.5 & -38.5 & -64.2 \\
\hline
\end{tabular}

Example 4: Let us concentrate on $\mathrm{NO}_{\mathrm{x}}$ emission at berth. The measured total emission amount for $\mathrm{NO}_{\mathrm{x}}$ from the main engine at berth is $2.248 \mathrm{~kg}$ for $T=0.4358 \mathrm{~h}$ (see Table 4). It follows that the measured hourly emission amount for $\mathrm{NO}_{\mathrm{x}}$ from the main engine at berth is $2.248 / 0.4358=5.158 \mathrm{~kg} / \mathrm{h}$. The measured total emission amount for $\mathrm{NO}_{\mathrm{x}}$ from the auxiliary engines at berth is $7.790 \mathrm{~kg}$ for $\mathrm{T}=2.632$ (see Table 5). It follows that the measured hourly emission amount for $\mathrm{NO}_{\mathrm{x}}$ from the auxiliary engines at berth is $7.790 / 2.632=2.960 \mathrm{~kg} / \mathrm{h}$. So, the measured combined hourly emission amount for $\mathrm{NO}_{\mathrm{x}}$ from all engines at berth will be $5.158+2.960=8.117 \mathrm{~kg} / \mathrm{h}$ (see Table 6).

Let us use the NERI inventory for $\mathrm{NO}_{\mathrm{x}}$ at berth. The NERI inventory deviation from the experimentally measured $2.248 \mathrm{~kg}$ total $\mathrm{NO}_{\mathrm{x}}$ emission amount from main engine at berth is $18.4 \%$ (see Table 4). It follows that NERI inventory deviation from the experimentally measured $5.158 \mathrm{~kg} / \mathrm{h}$ hourly $\mathrm{NO}_{\mathrm{x}}$ emission amount from $\mathrm{ME}$ at berth will be also $18.4 \%$. The NERI inventory deviation from the experimentally measured $7.790 \mathrm{~kg}$ total $\mathrm{NO}_{\mathrm{x}}$ emission amount from the auxiliary engines at berth is $-1.50 \%$ (see Table 5). It follows that NERI inventory deviation from the experimentally measured $2.960 \mathrm{~kg} / \mathrm{h}$ hourly $\mathrm{NO}_{\mathrm{x}}$ emission amount from the auxiliary engines at berth will be also $-1.50 \%$. So, the NERI inventories deviation from the experimentally measured $8.117 \mathrm{~kg} / \mathrm{h}$ combined hourly $\mathrm{NO}_{\mathrm{x}}$ emission amount from all engines at berth will be, $[18.4(5.158)-1.50(2.960)] / 8.117 \approx 11.2 \%$

That result is shown in Table 6.

The experimentally measured combined hourly emission amounts and the inventory predictions for all engines at berth are shown in Figure 3. The experimentally measured combined hourly emission amounts and the inventory deviations in \% from the experimental values for all engines at berth are given in Table 6 . The deviations in the last two columns of Table 6 are the same as the deviations in last two columns of Table 4 because there were no measurements of the $\mathrm{HC}$ and PM emissions from the auxiliary engines berth (see Table 1).

Most methods systemically over-predict the on-board measured combined hourly emission amounts of $\mathrm{NO}_{\mathrm{x}}$ and $\mathrm{HC}$, whereas systemically under-predict the on-board measured combined hourly emission amounts of $\mathrm{SO}_{\mathrm{x}}$ and $\mathrm{CO}_{2}$ when the vessel is at berth. The $\mathrm{CO}$ and PM inventories' predictions are somewhat scattered around the measured combined hourly emission amounts, although some under-prediction is present. The inventory predictions for $\mathrm{NO}_{\mathrm{x}}, \mathrm{SO}_{\mathrm{x}}, \mathrm{CO}_{2}$ and $\mathrm{PM}$ are somewhat satisfactory because the absolute deviations do not exceed $73.6 \%, 81.5 \%, 51.6 \%$, and $86.3 \%$ respectively. However, the inventory predictions for CO, and HC are completely unreliable with maximal absolute deviations reaching $1000 \%$, and $1390 \%$ respectively. 
Figure 2: Total Emission amounts' measurement and inventory prediction at berth for auxiliary engines
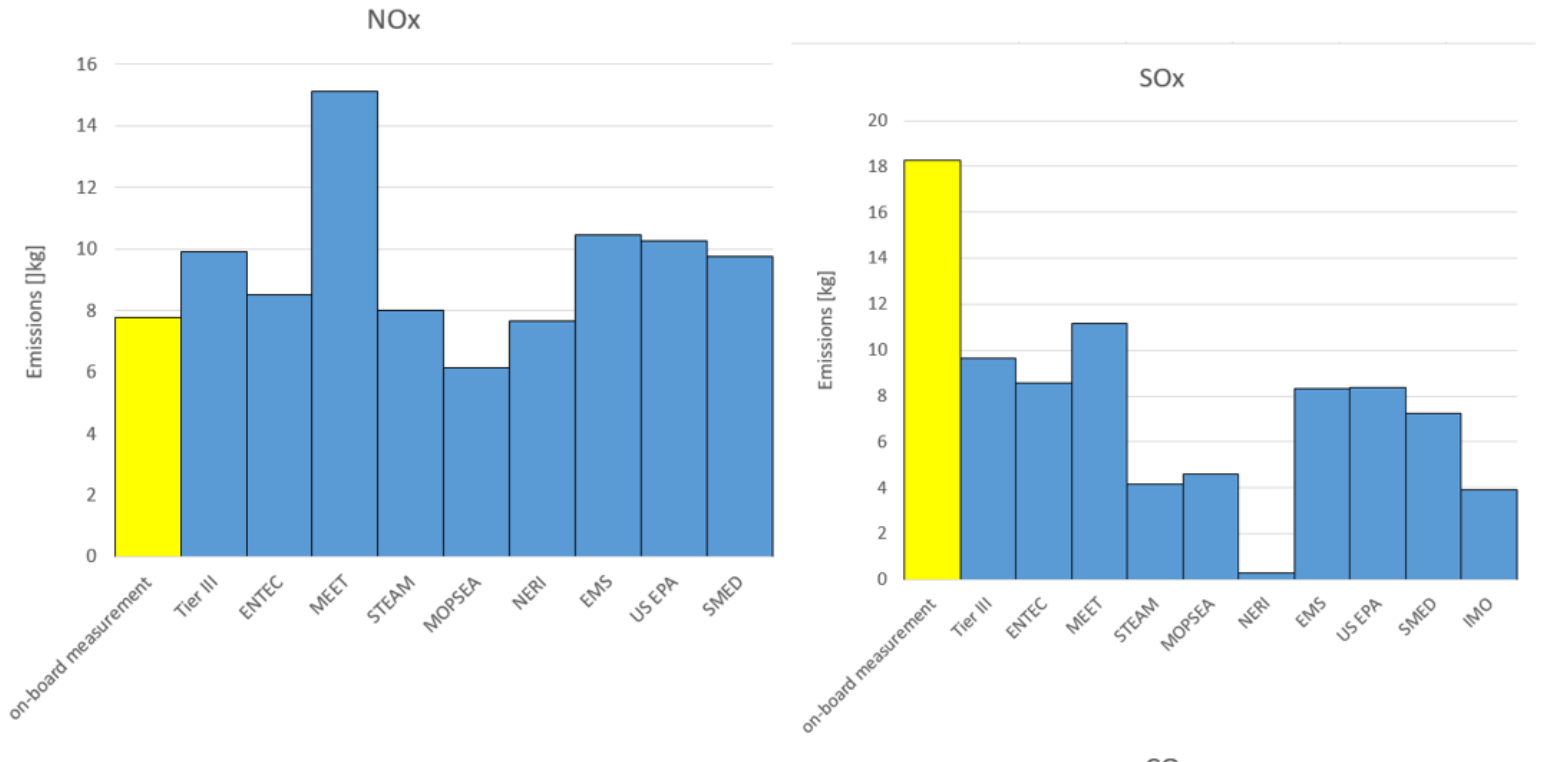

$\mathrm{CO} 2$

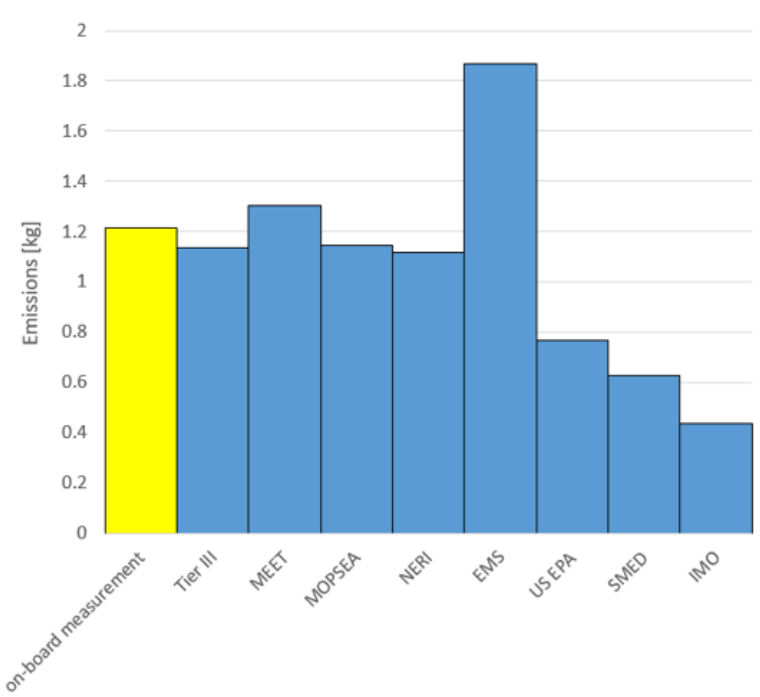

Table 6: Inventory deviations from the experimentally measured combined hourly emission amounts in $\%$ for the main engine plus the auxiliary engines at berth. The experimentally measured combined hourly emission amounts are given in the first row in $\mathrm{kg} / \mathrm{h}$. The mean absolute deviations in \% are shown in the last column

\begin{tabular}{|c|c|c|c|c|c|c|c|}
\hline Inventory & $\mathrm{NO}_{\mathrm{x}}$ & SO $_{\mathrm{x}}$ & $\mathrm{CO}_{2}$ & $\mathrm{CO}$ & HC & PM & MAD \\
\hline Experiment & 8.117 & 11.58 & 543.6 & 1.219 & 0.1806 & 1.289 & 0.000 \\
\hline Tier III & 34.2 & -13.3 & $\mathrm{NaN}$ & -2.58 & 350 & 7.62 & 81.5 \\
\hline ENTEC & 15.1 & -20.7 & -1.13 & $\mathrm{NaN}$ & 350 & 7.62 & 78.9 \\
\hline MEET & 27.2 & 7.56 & 16.6 & 1000 & 1390 & -86.3 & 422 \\
\hline STEAM & 73.6 & -59.9 & -11.5 & $\mathrm{NaN}$ & $\mathrm{NaN}$ & $\mathrm{NaN}$ & 48.3 \\
\hline MOPSEA & 36.0 & -58.5 & -8.58 & 1.83 & -41.0 & -47.5 & 32.2 \\
\hline NERI & 11.2 & -81.5 & -6.21 & 1.80 & 25.0 & -83.9 & 34.9 \\
\hline EMS & 61.9 & -25.2 & -6.69 & 69.7 & 45.0 & -41.7 & 41.7 \\
\hline US EPA & 52.7 & 9.43 & 51.6 & 401 & 987 & -77.7 & 263 \\
\hline IMO & 71.0 & -66.7 & -12.0 & -65.0 & 42.5 & -39.5 & 49.5 \\
\hline
\end{tabular}


Figure 3: Combined hourly emission amounts' measurement and inventory prediction at berth for the main engine plus the auxiliary engines
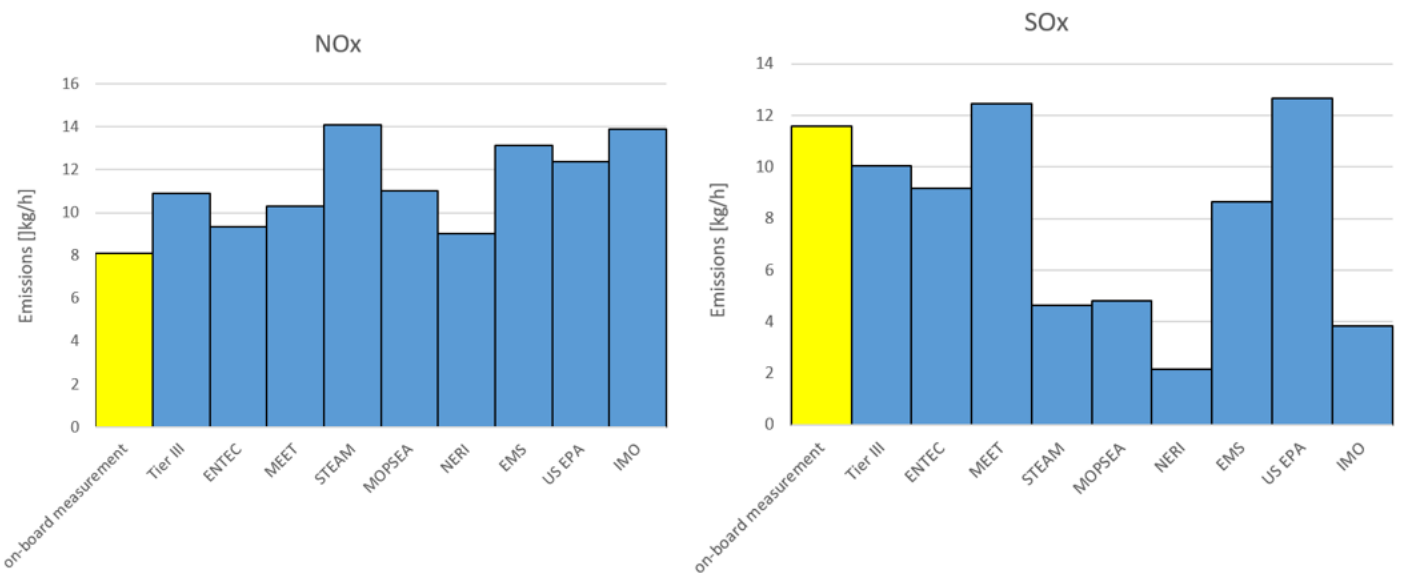

$\mathrm{CO} 2$
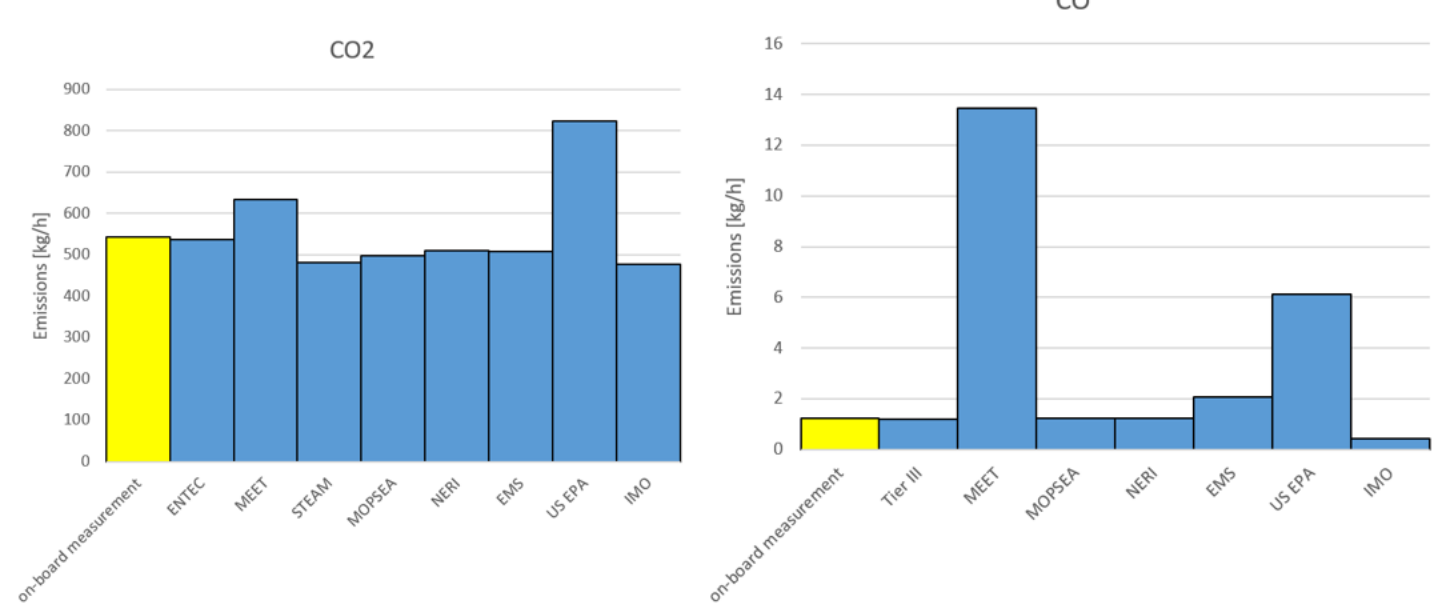

HC
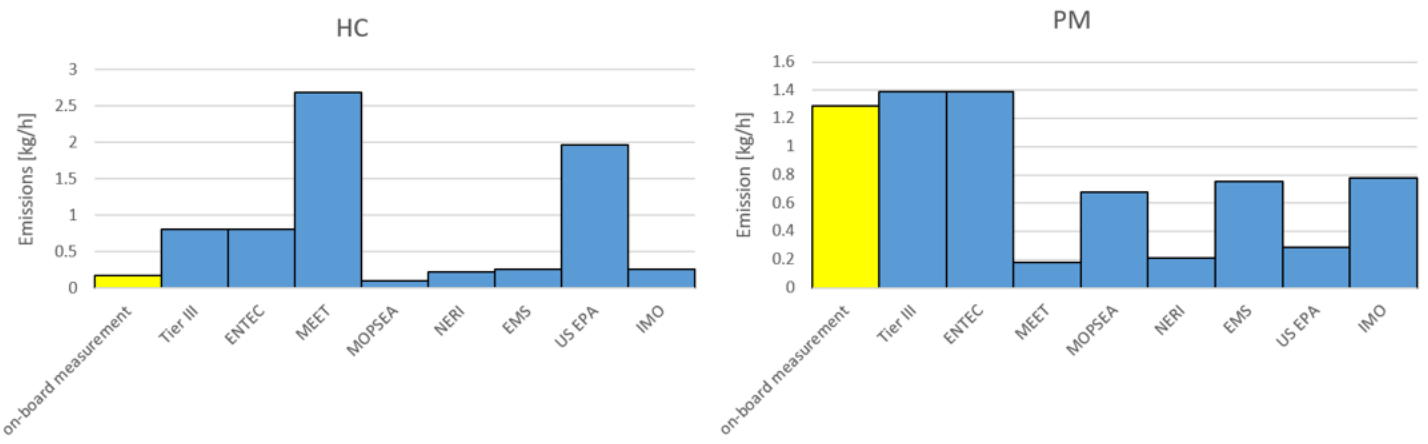

The inventories, which produce least absolute deviations from the experimentally measured combined hourly emission amounts at berth, are NERI for $\mathrm{NO}_{\mathrm{x}}, \mathrm{CO}$, and $\mathrm{HC}$ with $11.2 \%, 1.80 \%$, and $25.0 \%$ deviations respectively, MEET for $\mathrm{SO}_{\mathrm{x}}$ with $7.56 \%$ deviation, and ENTEC for $\mathrm{CO}_{2}$, and $\mathrm{PM}$ with $-1.13 \%$, and $7.62 \%$. Tier III for PM has the same result as ENTEC.

For each inventory family the mean value of its absolute deviations from the experimentally measured combined hourly emission amounts is shown in the last column of Table 6. With all its imperfections these values can serve as a "quick and dirty" marginalization of the 6-dimensional preference problem into a 1-dimensional ranking problem in ascending order of the Mean Absolute Deviation (MAD). All inventory families, which do not predict at least five of the six combined hourly emission amounts, are disqualified and their MADs are shown bolded in Table 6. According to the minimal MAD criterion the best inventory family at berth is MOPSEA with the $32.2 \%$ MAD. That family predicts all six of the emissions. The other inventory families, which predict all six of the combined hourly emission amounts, are MEET, NERI, EMS, US EPA, and IMO. 


\subsection{Inventories Performance when the Vessel is Maneuvering}

The experimentally measured total emission amounts and the inventory predictions for the main engine when the vessel is maneuvering are shown in Figure 4. The experimentally measured total emission amounts and the inventory deviations in \% from the experimental values for the main engine when maneuvering are given in Table 7.

\begin{tabular}{|c|c|c|c|c|c|c|c|}
\hline Inventory & $\mathrm{NO}_{\mathrm{x}}$ & SO $_{\mathrm{x}}$ & $\mathrm{CO}_{2}$ & CO & HC & PM & MAD \\
\hline Experiment & 51.17 & 61.28 & 3051 & 10.79 & 0.3772 & 10.18 & 0.000 \\
\hline Tier III & 21.7 & -9.26 & $\mathrm{NaN}$ & -39.1 & 653 & 40.8 & 153 \\
\hline ENTEC & 4.33 & -15.8 & -0.607 & $\mathrm{NaN}$ & 653 & 40.8 & 143 \\
\hline MEET & 53.9 & 3.09 & 5.45 & 161 & 222 & -84.2 & 88.3 \\
\hline STEAM & 69.5 & -56.5 & -9.26 & $\mathrm{NaN}$ & $\mathrm{NaN}$ & $\mathrm{NaN}$ & 45.1 \\
\hline MOPSEA & 75.6 & -56.4 & -9.41 & 29.1 & 59.3 & -7.90 & 39.6 \\
\hline NERI & 69.5 & 1.63 & -7.08 & -34.2 & 109 & 36.1 & 42.9 \\
\hline US EPA & 57.4 & 0.907 & 4.86 & -42.4 & 151 & -67.9 & 54.1 \\
\hline SMED & 18.2 & -28.1 & -0.670 & -59.2 & 149 & 52.5 & 51.3 \\
\hline IMO & 45.2 & -66.4 & -16.1 & -78.9 & 138 & -20.8 & 61.0 \\
\hline
\end{tabular}

Most methods systemically over-predict the on-board measured total emission amounts of $\mathrm{NO}_{\mathrm{x}}$, and $\mathrm{HC}$, whereas under-predict the $\mathrm{CO}_{2}$ emission amounts. The $\mathrm{SO}_{\mathrm{x}}, \mathrm{CO}$, and $\mathrm{PM}$ inventories' predictions are somewhat scattered around the measured total emission amounts for the main engine when the vessel is maneuvering. The $\mathrm{CO}_{2}$ is well predicted by every inventory method, with absolute deviations less than $16.1 \%$. The inventory predictions for $\mathrm{NO}_{\mathrm{x}}, \mathrm{SO}_{\mathrm{x}}$, and $\mathrm{PM}$ are somewhat satisfactory because the absolute deviations do not exceed 69.55, $66.4 \%$, and $84.2 \%$ respectively. However, the inventory predictions for CO, and HC are very unreliable with maximal absolute deviations reaching $161 \%$, and 653\% respectively.

The inventories, which produced least absolute deviations for the main engine when maneuvering, are MOPSEA for CO, HC, and PM with 29.1\%, 59.3\%, and -7.9\% deviations respectively, ENTEC for $\mathrm{NO}_{\mathrm{x}}$, and $\mathrm{CO}_{2}$ with $4.33 \%$, and $-0.607 \%$ deviations respectively, and NERI for $\mathrm{SO}_{\mathrm{x}}$ with $1.63 \%$ deviation.

For each inventory family the MAD criterion is shown in the last column of Table 7. All inventories, which do not predict at least five of the six total emission amounts, are disqualified and their mean values are shown with red in Table 7.

According to the minimal MAD criterion, the best inventory family for the main engine, when the vessel is maneuvering, is MOPSEA with the 39.6\% MAD. That family predicts all six of the emissions. The other inventory families which predict all six of the total emission amounts are MEET, NERI, US EPA, SMED, and IMO.

\subsection{Inventories Performance when the Vessel is Cruising}

In comparison to the other two operational modes (at berth and during maneuvering), more inventories are available for prediction of total emission amounts while the vessel is on cruising mode. The experimentally measured total emission amounts and the inventory predictions for the main engine when the vessel is cruising are shown in Figure 5. The experimentally measured total emission amounts and the inventory deviations in $\%$ from the experimental values for the main engine when cruising are given in Table 8. 
Figure 4: Total emission amounts' measurement and inventory prediction when maneuvering for the main engine

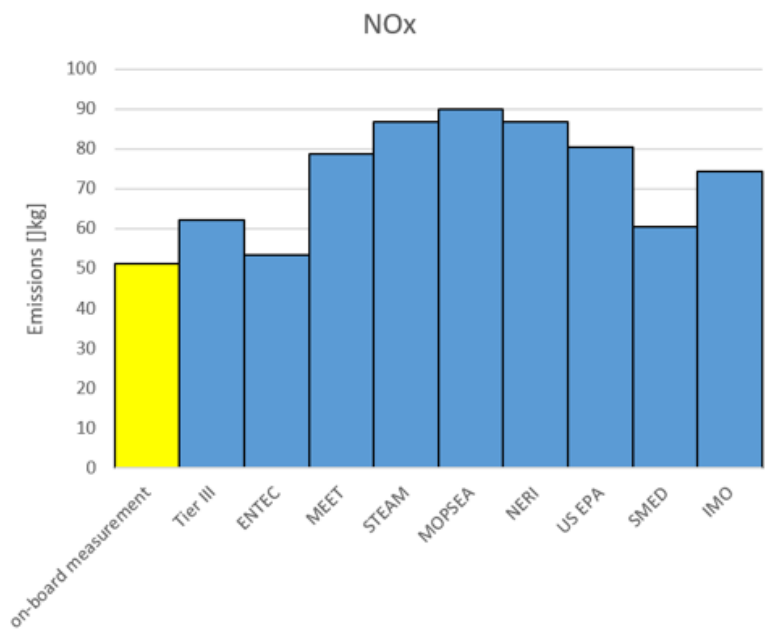

$\mathrm{CO} 2$

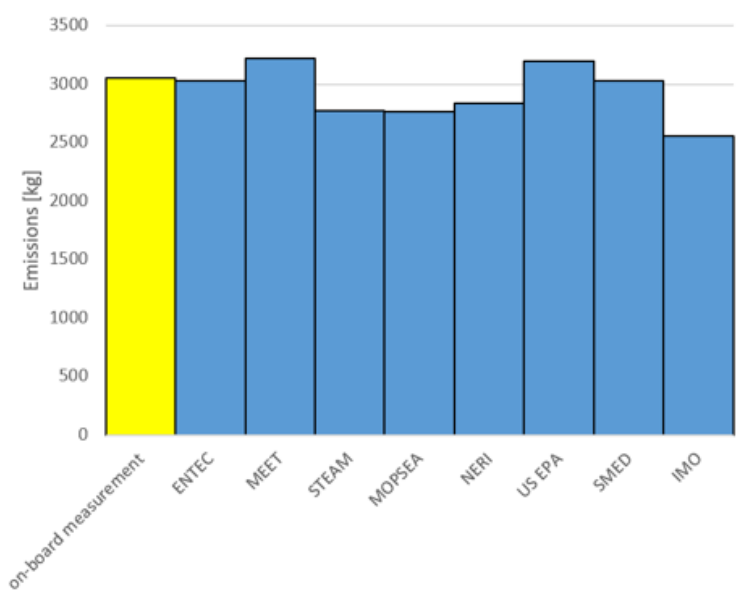

$\mathrm{HC}$

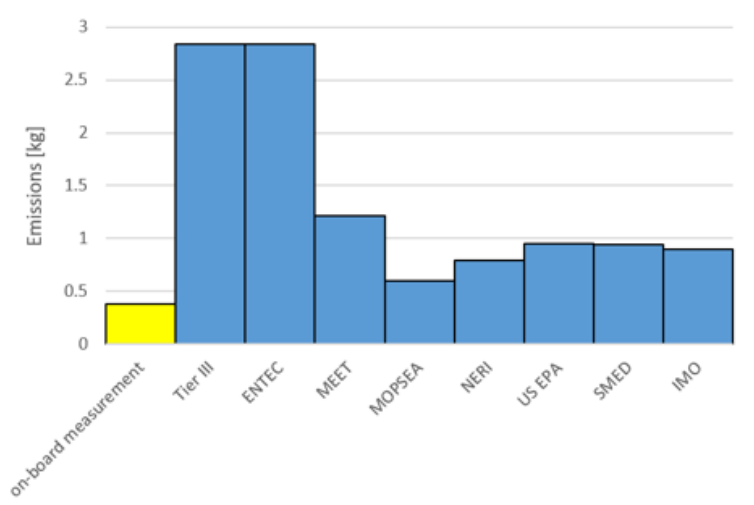

SOx

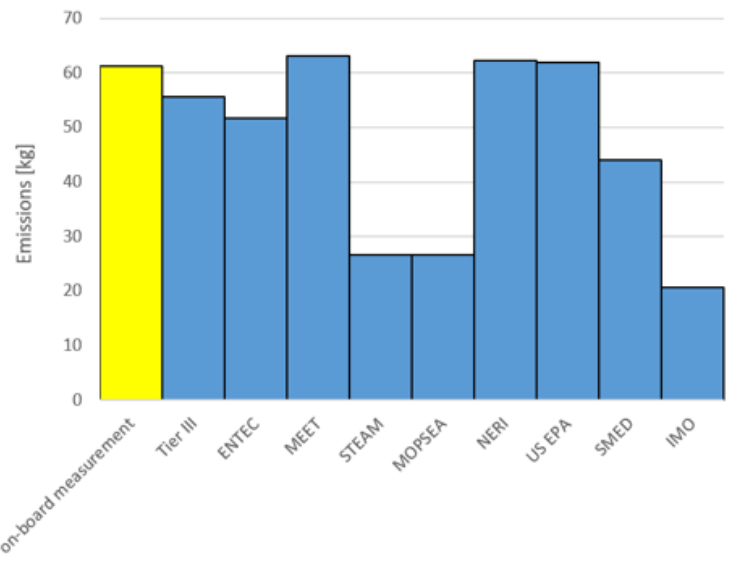

$\mathrm{CO}$

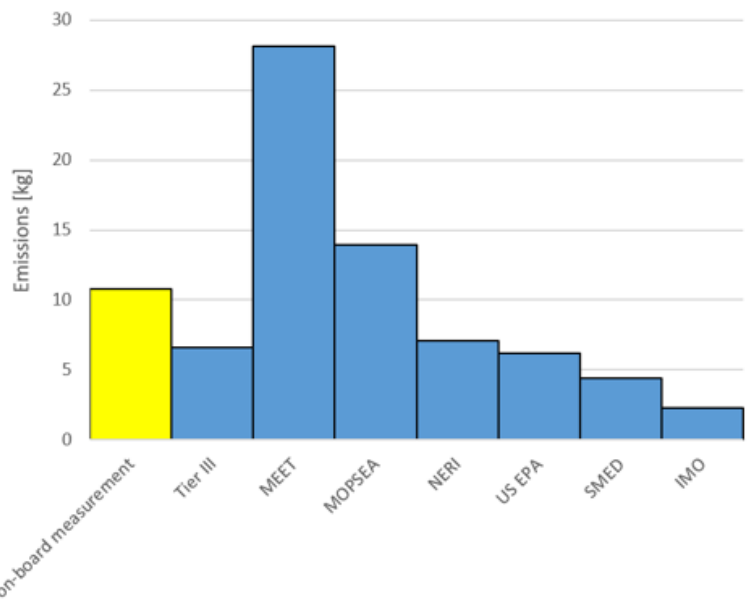

PM

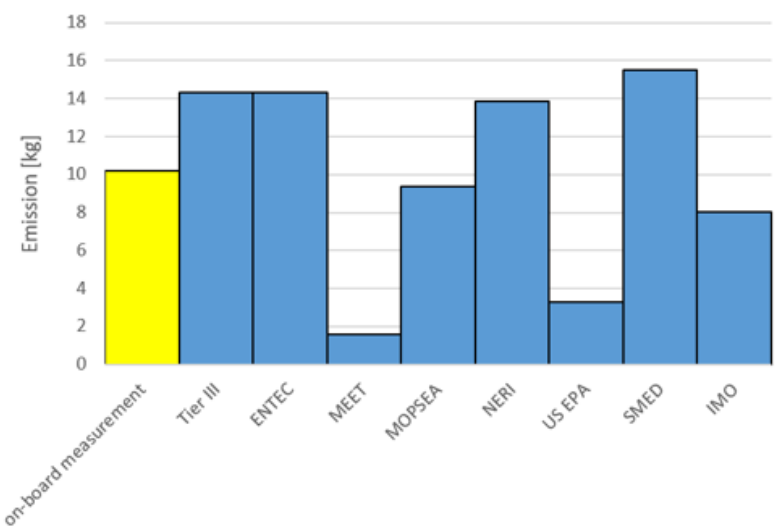

Most methods systemically under-predict the on-board measured total emission amounts of $\mathrm{NO}_{\mathrm{x}}, \mathrm{SO}_{\mathrm{x}}$, and $\mathrm{CO}_{2}$, whereas at the same time systemically over-predict the on-board measured total emission amounts of $\mathrm{CO}, \mathrm{HC}$, and $\mathrm{PM}$ from the main engine when the vessel is cruising. The $\mathrm{NO}_{\mathrm{x}}$ and $\mathrm{CO}_{2}$ are well predicted by every inventory method, with absolute deviations less than $21.0 \%$ and $24.6 \%$ respectively. The inventory predictions for $\mathrm{SO}_{\mathrm{x}}$ and CO also are somewhat satisfactory because the absolute deviations do not exceed $74.4 \%$ and $55.9 \%$ respectively. However, the inventory predictions for HC and PM are completely unreliable with maximal absolute deviations reaching $312 \%$ and $335 \%$ respectively. 
The inventories, which produce least absolute deviations for the main engine at cruising, are $\mathrm{MEET} \mathrm{for} \mathrm{SO}_{\mathrm{x}}$ $\mathrm{CO}_{2}$, and $\mathrm{PM}$ with $-28.7 \%,-13.9 \%$, and $-37.6 \%$ deviations respectively, STEAM for $\mathrm{NO}_{\mathrm{x}}$ with $-3.67 \%$ deviation, SMED for HC with $104 \%$ deviation, and jointly NERI \& US EPA for CO with $24.5 \%$ deviation.

For each inventory family the MAD criterion is shown in the last column of Table 8 . All inventories, which do not predict at least five of the six total emission amounts, are disqualified and their mean values are shown bolded in Table 8.

According to the minimal MAD criterion the best inventory family for the main engine, when the vessel is cruising is MEET with the 59.2\% MAD. That family predicts all six of the emissions. The other inventory families which predict all six of the total emission amounts, are MOPSEA, NERI, US EPA, SMED, and IMO.

Table 8. Inventory deviations from the experimentally measured total emission amounts in \% for the main engine at cruising. The experimental measurements are given in the first row in kg per time equal to the experiment duration according to the third column of Table 1 . The mean absolute deviations in $\%$ are shown in the last column

\begin{tabular}{lccccccc}
\hline Inventory & NO$_{\mathbf{x}}$ & SO $_{\mathbf{x}}$ & $\mathbf{C O}_{\mathbf{2}}$ & $\mathbf{C O}$ & HC & PM & MAD \\
\hline Experiment & 451.9 & 430.3 & 18180 & 26.76 & 4.401 & 11.80 & 0.000 \\
Tier I & -16.8 & -30.9 & NaN & 31.6 & 271 & 187 & 107 \\
Tier II & -5.78 & -30.9 & NaN & 31.6 & 312 & 299 & 136 \\
Tier III & -7.89 & -30.9 & NaN & 31.6 & 312 & 335 & 143 \\
Corbett & -10.5 & -44.7 & -14.3 & NaN & 312 & 220 & 120 \\
ENTEC & -21.0 & -42.0 & -18.9 & NaN & 312 & 335 & 146 \\
MEET & -5.78 & -28.7 & -13.9 & 35.1 & 234 & -37.6 & 59.2 \\
STEAM & -3.67 & -66.9 & -18.5 & NaN & NaN & NaN & $\mathbf{2 9 . 7}$ \\
MOPSEA & -6.31 & -66.8 & -18.6 & 36.0 & 79.1 & 276 & 80.5 \\
NERI & -4.73 & -30.3 & -14.4 & 24.5 & 312 & 268 & 109 \\
US EPA & -4.73 & -30.3 & -14.4 & 24.5 & 312 & 268 & 109 \\
SMED & -10.5 & -50.2 & -18.9 & -55.9 & 104 & 233 & 78.7 \\
IMO & -12.1 & -74.4 & -24.6 & -54.5 & 291 & 245 & 117 \\
\hline
\end{tabular}


Figure 5. Total emission amounts' measurement and inventory prediction when cruising for the main engine
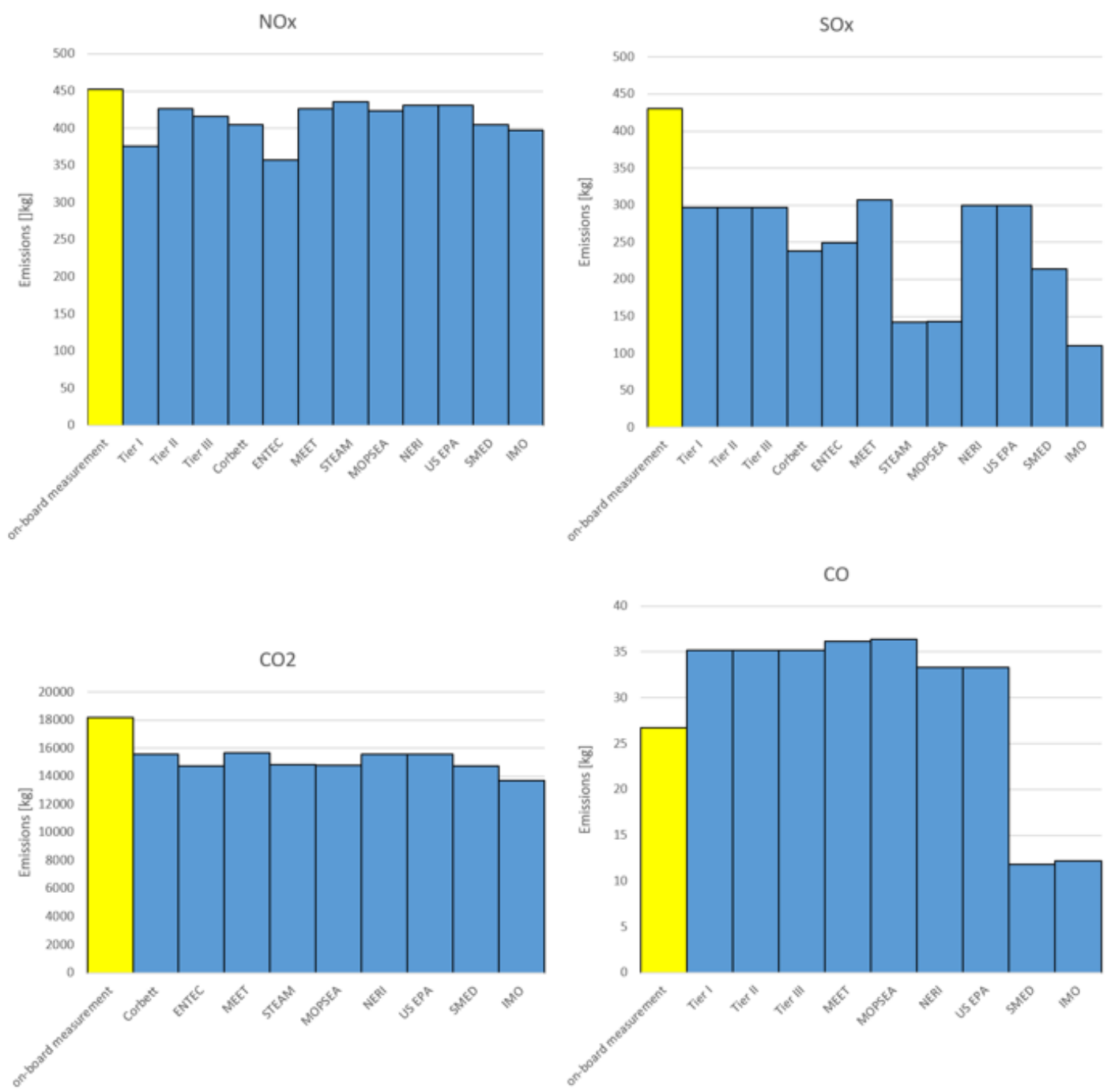

$\mathrm{HC}$

PM
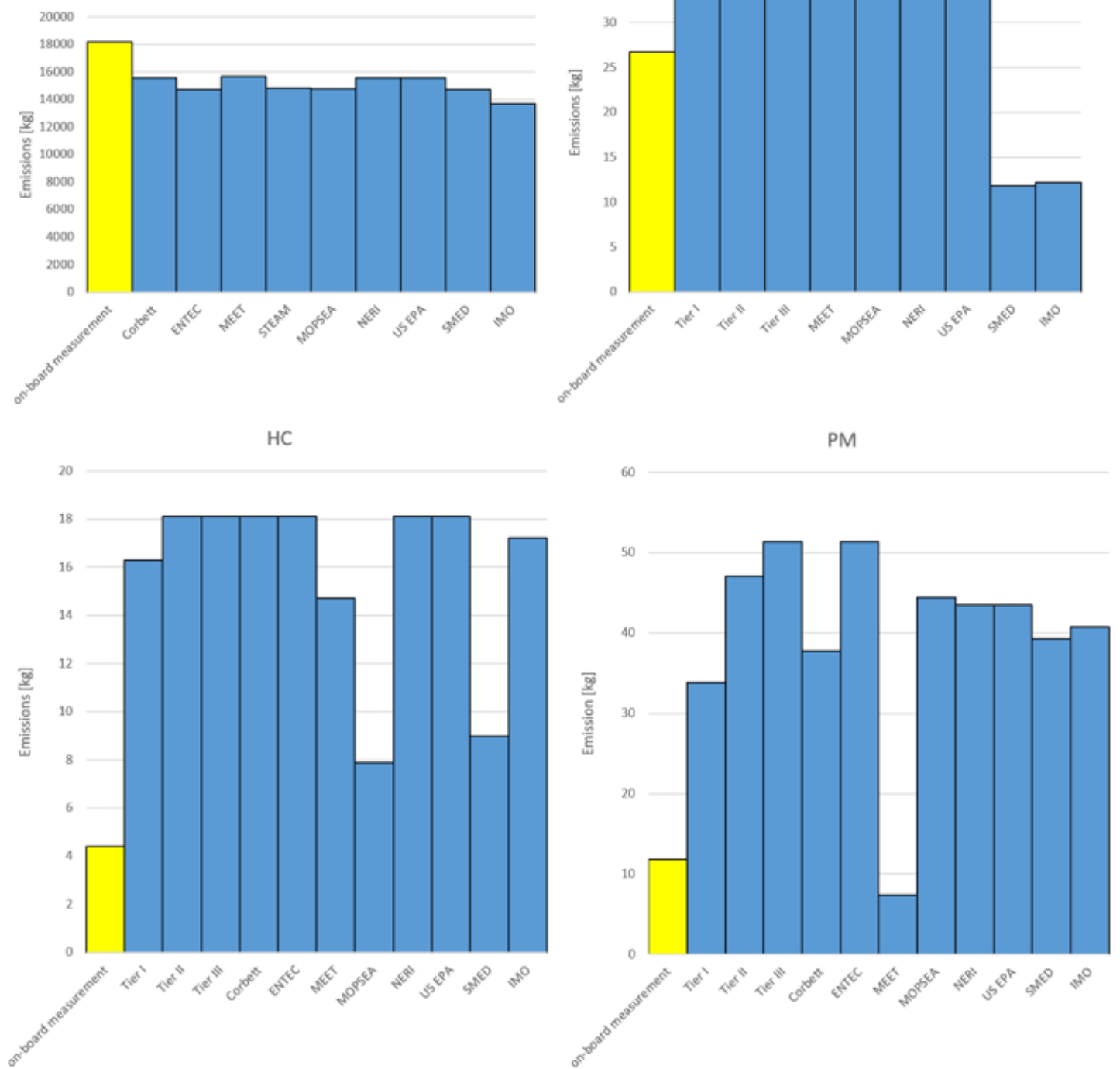


\section{Discussion}

\subsection{Improvement of the Minimal Mean Absolute Deviation Criterion}

A problem related to the case study described in sections 2 and 3 is the application of the minimal mean absolute deviation criterion to rank the inventory families under specific operational mode of the vessel. That criterion is not entirely rational, as it was pointed in the text. In this section we will discuss a more elaborate and rational method for ranking.

In section 3, we arranged the possible inventory methods according to preference three times (for each mode of operation). The preferences of any decision maker (DM) over a specific inventory family for a selected operational mode of a given vessel will depend only on the deviations of the inventory prediction emissions from the six emissions measured in the on-board experiment. Let us denote those deviations (in \%) as follows: $\Delta_{1}=\Delta \mathrm{NO}_{\mathrm{x}}, \Delta_{2}=\Delta \mathrm{SO}_{\mathrm{x}}, \Delta_{3}=\Delta \mathrm{CO}_{2}, \Delta_{4}=\Delta \mathrm{CO}, \Delta_{5}=\Delta \mathrm{HC}$ and $\Delta_{6}=\Delta \mathrm{PM}$. The six values can be organized in a 6-dimensional vector of deviations $\vec{\Delta}$ as follows:

$$
\vec{\Delta}=\left(\Delta_{1}, \Delta_{2}, \ldots, \Delta_{6}\right)=\left(\Delta \mathrm{NO}_{\mathrm{x}}, \Delta \mathrm{SO}_{\mathrm{x}}, \Delta \mathrm{CO}_{2}, \Delta \mathrm{CO}, \Delta \mathrm{HC}, \Delta \mathrm{PM}\right)
$$

The parameters $\Delta_{1}, \Delta_{2}, \ldots, \Delta_{6}$ in the terminology of decision analysis are called attributes. Some of the vectors can have one attribute missing (because some inventory families do not predict all six of the emissions). We need to rank those vectors for each of the operational modes of a vessel.

Example 5. In our case study during maneuvering, according to Table 7, we have six vectors (for MEET, MOPSEA, NERI, US EPA, SMED and IMO) with all 6 deviations:

$$
\begin{aligned}
& \vec{\Delta}_{\text {maneuvering }}^{\text {MEET }}=(53.9,3.09,5.45,161,222,-84.2) \\
& \vec{\Delta}_{\text {manewvering }}^{\text {MOPSEA }}=(75.6,-56.4,-9.41,29.1,59.3,-7.90) \\
& \vec{\Delta}_{\text {maneuvering }}^{\text {NERI }}=(69.5,1.63,-7.08,-34.2,109,36.1) \\
& \vec{\Delta}_{\text {maneuvering }}^{U S E P A}=(57.4,0.907,4.86,-42.4,151,-67.9) \\
& \vec{\Delta}_{\text {maneuvering }}^{\text {SMED }}=(18.2,-28.1,-0.670,-59.2,149,52.5) \\
& \vec{\Delta}_{\text {manewvering }}^{I M O}=(45.1,-66.4,-16.1,-78.9,138,-20.8)
\end{aligned}
$$

During maneuvering we also have two other vectors with missing values, but with at least four emission deviations calculated (for Tier III, and ENTEC):

$$
\begin{aligned}
& \vec{\Delta}_{\text {maneuvering }}^{\text {Tier III }}=(21.7,-9.26, \mathrm{NaN},-39.1,653,40.8) \\
& \vec{\Delta}_{\text {maneuvering }}^{\text {ENTEC }}=(4.33,-15.8,-0.607, \mathrm{NaN}, 653,40.8)
\end{aligned}
$$

In Section 3, we implicitly substituted the missing values with the mean of the known absolute deviations (that is with MAD). There are other more elaborate methods to impute missing values (Acock, 2005; Cohen, Cohen, West, \& Aiken, 2003), but this problem goes beyond the scope of the paper (see (Nikolova, Toneva-Zheynova, Naydenov, \& Tenekedjiev, 2012) for further discussion).

In section 3 we used the mean absolute deviation criterion to marginalize the stated six-dimensional preference problem into a one-dimensional ranking problem. However, it has been stated in this paper that the criterion in question is "quick and dirty". Completely rational decisions can be obtained if a value function is built, which accurately reflects the preferences of the DM. The function will be additive because the DM holds the mutual preferential independence over the 6 attributes: from two inventories, the DM will prefer the one that has more favorable deviation for any attribute, if the rest of the attributes are pair-wise equal, and the decision will never depend on the equal deviations (French \& Insua, 2010). That is why, it is possible to construct a value function over the vector of deviations in the form: 


$$
\begin{aligned}
& v(\vec{\Delta})=v\left(\Delta \mathrm{NO}_{\mathrm{x}}, \Delta \mathrm{SO}_{\mathrm{x}}, \Delta \mathrm{CO}_{2}, \Delta \mathrm{CO}, \Delta \mathrm{HC}, \Delta \mathrm{PM}\right)= \\
& =a_{1} v_{1}\left(\Delta \mathrm{NO}_{\mathrm{x}}\right)+a_{2} v_{2}\left(\Delta \mathrm{SO}_{\mathrm{x}}\right)+a_{3} v_{3}\left(\Delta \mathrm{CO}_{2}\right)+a_{4} v_{4}(\Delta \mathrm{CO})+a_{5} v_{5}(\Delta \mathrm{HC})+a_{6} v_{6}(\Delta \mathrm{PM})
\end{aligned}
$$

The inventories have to be ranked in descending order of the value function. The value function is normalized in the closed interval $[0 ; 1]$ in a sense that it should be 1 if all deviations are $0 \%$ (the best-case scenario) and it should be 0 , if all deviations are $-100 \%$ (the worst-case scenario). In the above equation, the constants $a_{i}$, for $i=1$, $2, \ldots, 6$ are the weight coefficients, which reflect the importance of each attribute into the overall preference of the DM over the six-dimensional vectors $\vec{\Delta}$. Each of the six constants should be non-negative and they should sum to one. The one-dimensional functions $v_{i}($.$) , for i=1,2, \ldots, 6$ are the attribute value functions over each of the emission deviations (which are value-difference functions (French \& Insua, 2010)). Each of $v_{i}($.$) is normalized so that$ $v_{i}(-100 \%)=0, v_{i}(0 \%)=1$, and $\lim _{\Delta_{i} \rightarrow \infty} v_{i}\left(\Delta_{i}\right)=0$. The function should increase from $-100 \%$ to $0 \%$ and decrease from $0 \%$ to "plus infinity" \%. An example of such a function is given on Figure 6.

It is perfectly rational that the attribute value functions are different for each of the attributes and for each of the vessel modes of operation. Alternatively, the DM may use one and the same function over each attribute for each mode, since they all measure the opinion of the DM regarding the precision of predictions. The form of the attribute value functions depends solely on the preferences of the DM. There is not much discussion in literature regarding the rational construction of value functions. However, as far as value functions are a special case of utility functions under risk, then the techniques for construction of such functions may be adopted for the case of value functions. The single attribute utility function is constructed usually by eliciting several nodes of their function and then applying either an analytical non-linear function to approximate the utility on the elicited nodes, or linear function to interpolate over the elicited nodes. We will demonstrate how to elicit several nodes of the onedimensional function $v_{i}\left(\right.$.). It is already known that $v_{i}(-100 \%)=0, v_{i}(0 \%)=1$, and $\lim _{\Delta_{i} \rightarrow \infty} v_{i}\left(\Delta_{i}\right)=0$. The DM can select a set of $M$ additional deviation values $\left\{\Delta_{i, 1}, \Delta_{i, 2}, \ldots, \Delta_{i, M}\right\}$ for the $i^{\text {th }}$ emission. In order to find the value of the onedimensional function $v_{i}\left(\Delta_{i, j}\right)$ at the deviation $\Delta_{i, j}$ the DM has to identify the probability $p_{j}$ where he/she is indifferent between:

A) the option of getting $\Delta_{i, \text { best }}=0 \%$ with probability $p_{j}$ or getting $\Delta_{i, \text { worst }}=-100 \%$ with probability $\left(1-p_{j}\right)$. This option is denoted as $<\Delta_{i, b e s t}\left(p_{j}\right) \Delta_{i, w o r s t}>$.

B) the option of getting a deviation $\Delta_{i, j}$ for sure.

If $p_{j}$ is identified by the DM so that the latter is indifferent between the two stated options, then $v_{i}\left(\Delta_{i, j}\right)=p_{j}$. In fact, the DM has to solve $M$ preferential equations of the type $<\Delta_{i, \text { best }}\left(p_{j}\right) \Delta_{i, \text { worst }}>\sim \Delta_{i, j}$ where the symbol $\sim$ stands for indifference. The recommended method to elicit such nodes is called probability equivalence method, but there are other more complicated methods (see French \& Insua, 2010 as well as Nikolova, Hirota, Kobashikawa \& Tenekedjiev, 2006) for discussion on methods to elicit nodes of one-dimensional value functions).

The weight coefficients in the value function measure the importance of each pollutant in the overall assessment of preferences over emission inventories. It is only natural to expect that pollution levels have different significance depending on the regime - pollution close or in ports are causing more direct harm than emissions while at sea, while still the pollution is of global importance. There are elaborate methods to elicit the weight coefficients, which are nothing else but scaling constants in the utility theory. Scaling constants are elicited subjectively, where the DM has to identify the probability $p_{i}$, which makes him/her indifferent when comparing:

A) the option of getting $\vec{\Delta}_{\text {best }}=(0,0,0,0,0,0)$ with probability $p_{i}$ or getting

$\vec{\Delta}_{\text {worst }}=(-100,-100,-100,-100,-100,-100)$ with probability $\left(1-p_{i}\right)$. This option is denoted as $<\vec{\Delta}_{\text {best }}\left(p_{i}\right) \vec{\Delta}_{\text {worst }}>$.

B) the option of getting for sure a deviation vector, where only the $i$-th deviation is set to its best level $0 \%$, and the others are at their worst level of $-100 \%$ : 
$\vec{\Delta}_{\text {corner }, i}=\left(\Delta_{1}=-100, \ldots, \Delta_{i-1}=-100, \Delta_{i}=0, \Delta_{i+1}=-100, \ldots, \Delta_{n}=-100\right)$. Such vector is a.k.a. corner vector.

If $p_{i}$ is identified by the DM so that the latter is indifferent between the two stated options, then $a_{i}=p_{i}$. In fact, the DM has to solve six preferential equations of the type $<\vec{\Delta}_{\text {best }}\left(p_{i}\right) \vec{\Delta}_{\text {worst }}>\sim \vec{\Delta}_{\text {corner }, i}$ (see Keeney \& Raiffa, 1993) for detailed discussion on multi-dimensional utility functions and identification of scaling constants).

Figure 6: Example of the value functions $v_{i}($.$) over an emission deviation (continues line). The function$ $v_{q u i c k}\left(\Delta_{i}\right)=1-\left|\Delta_{i}\right| / 100$ is shown for reference (dashed line)

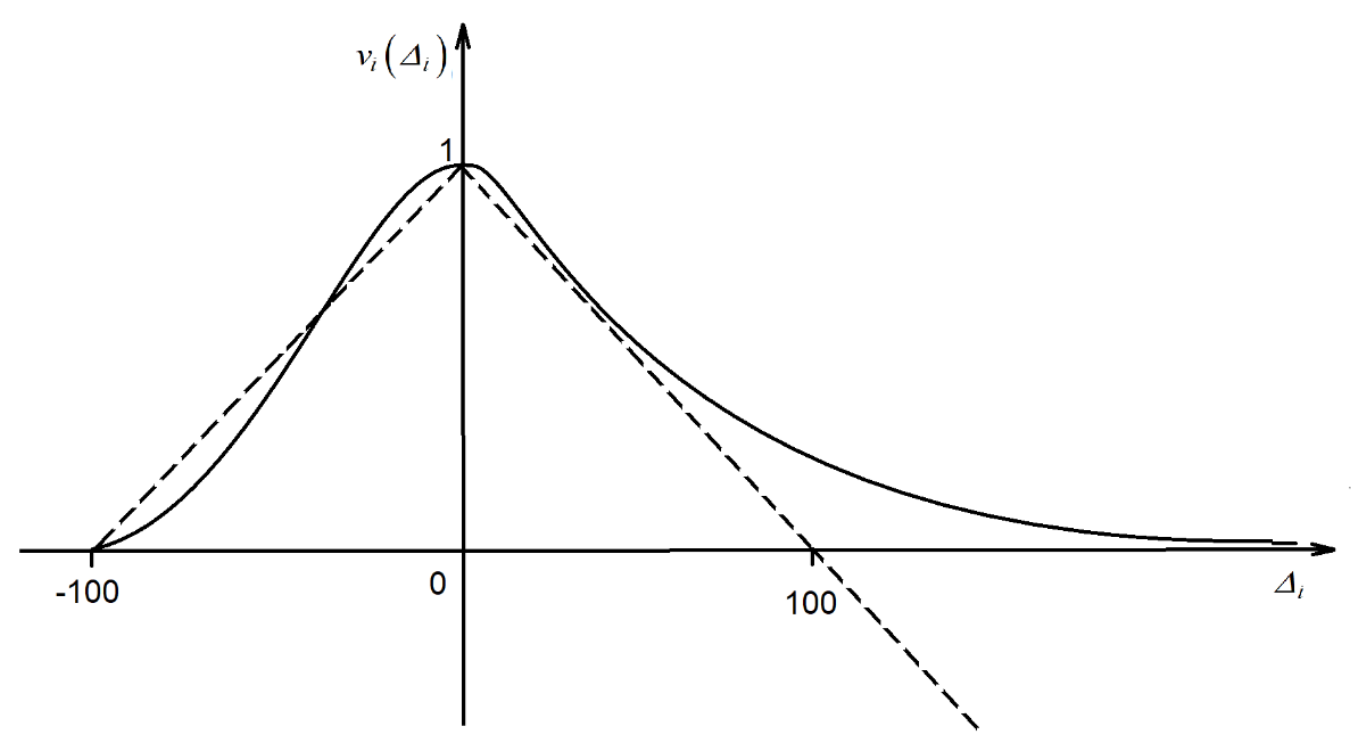

\subsection{Choosing the Best Inventory Family for a Given Type of Operation}

Constructing the value functions, we will be able to choose which inventory method is the best (most preferred) for each operational mode. The following algorithm can be utilized to select the best inventory method for a given type of ship operation:

\section{Algorithm to select the best inventory method for a selected type of operation:}

1. Define the vector of deviations $\vec{\Delta}=\left(\Delta \mathrm{NO}_{\mathrm{x}}, \Delta \mathrm{SO}_{\mathrm{x}}, \Delta \mathrm{CO}_{2}, \Delta \mathrm{CO}, \Delta \mathrm{HC}, \Delta \mathrm{PM}\right)$ for each inventory method (with at least five emission deviations calculated).

2. Impute missing values in the vector of deviations by replacing them with the mean of the known deviations' absolute values.

3. Construct the attribute value functions $v_{i}($.$) for the selected type of operation.$

4. Elicit the scaling constants $a_{i}$ for $i=1,2, \ldots, 6$ for the selected type of operation.

5. Construct the value function $v$ as function of six attributes and their scaling constants.

6. Calculate $v(\vec{\Delta})$ for each of the deviation vectors from step 1 ).

7. Choose the inventory family that has the highest value, calculated in step 6).

While our algorithm assumes we need at least five calculated deviations (in step 1), this requirement may be modified and is prescriptive, not mandatory. If all six deviations are calculated, then step 2 of the above algorithm will be obsolete. We will demonstrate the application of this algorithm in an example. 
Example 6. Let us select the best inventory method for operation during maneuvering. There are eight vectors that satisfy step 1 of the Algorithm (that at least five pollution deviations are calculated) and they were given in Example 5.

Following step 2 of the Algorithm, we identify the following imputed values for the two vectors containing missing values. For the inventory Tier III, the deviation in $\mathrm{CO}_{2}$ will be:

$$
\Delta_{3}=\left(\left|\Delta_{1}\right|+\left|\Delta_{2}\right|+\left|\Delta_{4}\right|+\left|\Delta_{5}\right|+\left|\Delta_{6}\right|\right) / 5=(21.7+9.26+39.1+653+40.8) / 5 \approx 153=\mathrm{MAD}^{\text {TIER III }}
$$

Then $\vec{\Delta}_{\text {maneuvering }}^{\text {Tier III }}=(21.7,-9.26,153,-39.1,653,40.8)$.

For the inventory family ENTEC, the deviation in $\mathrm{CO}$ will be:

$$
\Delta_{4}=\left(\left|\Delta_{1}\right|+\left|\Delta_{2}\right|+\left|\Delta_{3}\right|+\left|\Delta_{5}\right|+\left|\Delta_{6}\right|\right) / 5=(4.33+15.8+0.607+653+40.8) / 5 \approx 143=\mathrm{MAD}^{E N T E C}
$$

Then $\vec{\Delta}_{\text {maneuvering }}^{\text {ENTEC }}=(4.33,-15.8,-0.607,143,653,40.8)$.

Following step 3 of the Algorithm, let the DM believe that all attribute value functions are the same and are equal to $v_{s a}($.$) :$

$$
v_{1}(.) \equiv v_{2}(.) \equiv \ldots \equiv v_{6}(.) \equiv v_{s a}(.) \text {. }
$$

The following preferential equations were solved in order to elicit additional nodes from $v_{s a}($.$) :$

$$
\begin{aligned}
& <0 \%(0.17)-100 \%>\sim-75 \%=>v_{s a}(-75 \%)=0.17 \\
& <0 \%(0.40)-100 \%>\sim-50 \%=>v_{s a}(-50 \%)=0.40 \\
& <0 \%(0.75)-100 \%>\sim-25 \%=>v_{s a}(-25 \%)=0.75 \\
& <0 \%(0.75)-100 \%>\sim 25 \%=>v_{s a}(25 \%)=0.75 \\
& <0 \%(0.60)-100 \%>\sim 50 \%=>v_{s a}(50 \%)=0.60 \\
& <0 \%(0.50)-100 \%>\sim 75 \%=>v_{s a}(75 \%)=0.50 \\
& <0 \%(0.429)-100 \%>\sim 100 \%=>v_{s a}(100 \%)=0.429 \approx 0.43 \\
& <0 \%(0.273)-100 \%>\sim 200 \%=>v_{s a}(200 \%)=0.273 \approx 0.27 \\
& <0 \%(0.20)-100 \%>\sim 300 \%=>v_{s a}(300 \%)=0.20
\end{aligned}
$$

The function $v_{s a}($.$) is then approximated with the following analytical form:$

$$
v_{s a}(x)= \begin{cases}\frac{100+x}{75-x} & \text { for }-100 \leq x \leq-25 \\ \frac{2500-x^{2}}{2500} & \text { for }-25<x<25 \\ \frac{75}{x+75} & \text { for } x \geq 25\end{cases}
$$

Figure 7 presents the approximated function $v_{s a}(x)$, for $x \in[-100 ; \infty$ ) (we can see the similarities of this function to the example one presented on Figure 6). 
Figure 7: Graphics of the single attribute function $v_{s a}(x)$

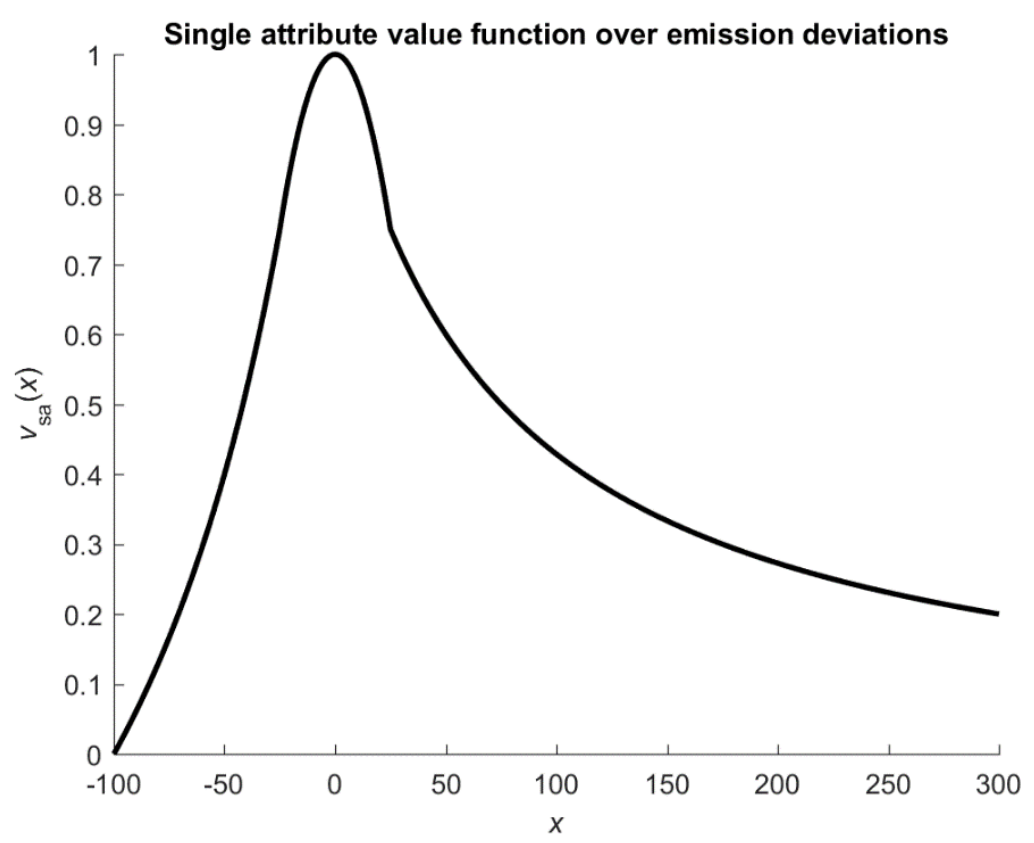

The DM has also elicited the following scaling constants:

$$
\begin{aligned}
& <\vec{\Delta}_{\text {best }}(0.10) \vec{\Delta}_{\text {worst }}>\sim \vec{\Delta}=(-100,0,0,0,0,0)=>a_{1}=0.10 \\
& <\vec{\Delta}_{\text {best }}(0.25) \vec{\Delta}_{\text {worst }}>\sim \vec{\Delta}=(0,-100,0,0,0,0)=>a_{2}=0.25 \\
& <\vec{\Delta}_{\text {best }}(0.05) \vec{\Delta}_{\text {worst }}>\sim \vec{\Delta}=(0,0,-100,0,0,0)=>a_{3}=0.05 \\
& <\vec{\Delta}_{\text {best }}(0.30) \vec{\Delta}_{\text {worst }}>\sim \vec{\Delta}=(0,0,0,-100,0,0)=>a_{4}=0.30 \\
& <\vec{\Delta}_{\text {best }}(0.10) \vec{\Delta}_{\text {worst }}>\sim \vec{\Delta}=(0,0,0,0,-100,0)=>a_{5}=0.10 \\
& <\vec{\Delta}_{\text {best }}(0.20) \vec{\Delta}_{\text {worst }}>\sim \vec{\Delta}=(0,0,0,0,0,-100)=>a_{6}=0.20
\end{aligned}
$$

Following step 4 of the Algorithm, the six-attribute value function is constructed:

$$
\begin{aligned}
& v(\vec{\Delta})=v\left(\Delta \mathrm{NO}_{\mathrm{x}}, \Delta \mathrm{SO}_{\mathrm{x}}, \Delta \mathrm{CO}_{2}, \Delta \mathrm{CO}, \Delta \mathrm{HC}, \Delta \mathrm{PM}\right)= \\
& =0.10 v_{s a}\left(\Delta \mathrm{NO}_{\mathrm{x}}\right)+0.25 v_{s a}\left(\Delta \mathrm{SO}_{\mathrm{x}}\right)+0.05 v_{s a}\left(\Delta \mathrm{CO}_{2}\right)+0.30 v_{s a}(\Delta \mathrm{CO})+0.10 v_{s a}(\Delta \mathrm{HC})+0.20 v_{s a} \Delta \mathrm{PM}
\end{aligned}
$$

Following step 5 of the Algorithm, we can calculate the value function over each of the inventories. For example, for MEET we have:

$$
\begin{aligned}
& v\left(\vec{\Delta}_{\text {maneuvering }}^{\text {MEET }}\right)=v(53.9,3.09,5.45,161,222,-84.2) \\
& =0.10 v_{s a}(53.9)+0.25 v_{s a}(3.09)+0.05 v_{s a}(5.45)+0.30 v_{s a}(161)+0.10 v_{s a}(222)+0.20 v_{s a}(-84.2) \\
& =0.10 \times 0.5818+0.25 \times 0.9962+0.05 \times 0.9881+0.30 \times 0.3178+0.10 \times 0.2525+0.20 \times 0.0992 \\
& =0.4971
\end{aligned}
$$


In the same way we can calculate the value function over the other seven inventory families:

$$
\begin{aligned}
& v\left(\vec{\Delta}_{\text {maneuvering }}^{\text {MOPSA }}\right)=v(75.6,-56.4,-9.41,29.1,59.3,-7.90)=\ldots=0.6480 \\
& v\left(\vec{\Delta}_{\text {maneuvering }}^{\text {NERI }}\right)=v(69.5,1.63,-7.08,-34.2,109,36.1)=\ldots=0.7072 \\
& v\left(\vec{\Delta}_{\text {maneuvering }}^{\text {US EPA }}\right)=v(57.4,0.907,4.86,-42.4,151,-67.9)=\ldots=0.5814 \\
& v\left(\vec{\Delta}_{\text {maneuvering }}^{\text {SMED }}\right)=v(18.2,-28.1,-0.670,-59.2,149,52.5)=\ldots=0.5534 \\
& v\left(\vec{\Delta}_{\text {maneuvering }}^{I \text { IMO }}\right)=v(45.2,-66.4,-16.1,-78.9,138,-20.8)=\ldots=0.4083 \\
& v\left(\vec{\Delta}_{\text {maneuvering }}^{\text {Tier III }}\right)=v(21.7,-9.26,153,-39.1,653,40.8)=\ldots=0.6390 \\
& v\left(\vec{\Delta}_{\text {maneuvering }}^{\text {ENTEC }}\right)=v(4.33,-15.8,-0.607,143,653,40.8)=\ldots=0.6173
\end{aligned}
$$

Following step 6 of the Algorithm the recommended inventory family when maneuvering would be MEET, because it has the highest value of the value function (0.7072). The second-best inventory family would be MOPSEA with value function of 0.6468 . The selection of the MEET inventory family is a slight improvement compared to the one achieved with the minimal MAD criterion in section 3.2, where the MOPSEA was selected.

Let us assume that the DM wants to use the same attribute value function for all six attributes in the form $v_{\text {quick }}\left(\Delta_{i}\right)=1-\left|\Delta_{i}\right| / 100$. This function is shown with dashed line on Figure 6, where it can be seen it somehow resembles the "precise and rational" $v_{i}\left(\Delta_{i}\right)$ given with solid line. Let the same DM be happy to use six equal scaling constants and therefore $a_{i}=1 / 6$ for $i=1,2, \ldots, 6$. The main advantage of using the $v_{\text {quick }}($.$) with equal weight$ coefficients is that the six attribute value function can be built quickly by skipping the elaborate procedure in Section 4.1 and demonstrated in Example 6. The function $v_{q u i c k}\left(\Delta_{i}\right)$ is not normalized because it takes negative values for deviations greater than $100 \%$. However, the only place where this normalization matters is the skipped procedure for elicitation of the scaling constants using corner vectors. So, the six-attribute value function which models the preference of the discussed DM will take the form:

$$
\begin{aligned}
& v(\vec{\Delta})=v\left(\Delta \mathrm{NO}_{\mathrm{x}}, \Delta \mathrm{SO}_{\mathrm{x}}, \Delta \mathrm{CO}_{2}, \Delta \mathrm{CO}, \Delta \mathrm{HC}, \Delta \mathrm{PM}\right)= \\
& =\frac{1}{6} v_{\text {quick }}\left(\Delta \mathrm{NO}_{\mathrm{x}}\right)+\frac{1}{6} v_{\text {quick }}\left(\Delta \mathrm{SO}_{\mathrm{x}}\right)+\frac{1}{6} v_{\text {quick }}\left(\Delta \mathrm{CO}_{2}\right)+\frac{1}{6} v_{\text {quick }}(\Delta \mathrm{CO})+\frac{1}{6} v_{\text {quick }}(\Delta \mathrm{HC})+\frac{1}{6} v_{\text {quick }}(\Delta \mathrm{PM})= \\
& =\frac{1-\left|\Delta \mathrm{NO}_{\mathrm{x}}\right| / 100}{6}+\frac{1-\left|\Delta \mathrm{SO}_{\mathrm{x}}\right| / 100}{6}+\frac{1-\left|\Delta \mathrm{CO}_{2}\right| / 100}{6}+\frac{1-|\Delta \mathrm{CO}| / 100}{6}+\frac{1-|\Delta \mathrm{NC}| / 100}{6}+\frac{1-|\Delta \mathrm{PM}| / 100}{6}= \\
& =1-\frac{1}{100} \frac{\left|\Delta \mathrm{NO}_{\mathrm{x}}\right|+\left|\Delta \mathrm{SO}_{\mathrm{x}}\right|+\left|\Delta \mathrm{CO}_{2}\right|+|\Delta \mathrm{CO}|+|\Delta \mathrm{HC}|+|\Delta \mathrm{PM}|}{6}=1-\frac{1}{100} w(\vec{\Delta})
\end{aligned}
$$

It is obvious that under the discussed circumstances the value function $v($.$) is a negative affine transformation$ of the MAD criterion $w($.). So according to the value function uniqueness theorem (French, 1993) the maximization of the six-attribute value function $v($.$) will produce the same result as the application of the minimal MAD criterion.$ The later happens to be a special case of the six-attribute value function $v($.$) , where the scaling constants are equal,$ and the six attribute functions are in the form $v_{\text {quick }}\left(\Delta_{i}\right)=1-\left|\Delta_{i}\right| / 100$. That is why the ranking of inventory families with the minimal MAD criterion is "quick and dirty" approach, which often produce satisfactory results as in Example 6. However, using the more elaborate 6-atrribute value function approach will guarantee that the selected inventory family will fully correspond to the DM preferences as is the case presented in Example 6. 


\subsection{Policy Implications of the Case Study}

We can formulate some implications from the case study given in sections 2 and 3 and improved in Sections 4.1 and 4.2. It is very likely that for any standard ship in a specific mode of operation there is an inventory method that will produce emission predictions with high precision. If on-board measurement experiments are available, we have a chance of identifying which is the most suitable method and from what we demonstrated in the paper, this is a comparatively easy task. The best inventory method will most likely give small deviations from the measured emissions. However, if we try to choose blindly one inventory family for some mode of operation (without backing this up by any real time measurements) there is a high chance that we will choose a method that produces unacceptably high errors. The case study demonstrated that some methods deviate substantially in their predictions (by well over 100\%). In that sense, one of the important contributions of this paper is to demonstrate the importance of experimental data to identify suitable inventory family for each of vessel's modes of operation.

This case study demonstrated an efficient way forward for emission estimation of a ship during technical exploitation in a quick and precise manner. It is possible that on-board measurements of the ship emission can be conducted at the time the ship is put in exploitation as well as at times of regular ship repairs. Using those measurements, the inventory method, which predicts the emissions with minimal error can be identified for each mode of operation of the vessel. The identified inventory methods can be used by various regulatory authorities during exploitation of the ship to calculate emissions during regular exploitation. The discussed inventory methods are beneficial first of all for the policy makers, who need to assess the pollution caused by shipping in order to implement reasonable boundaries to that pollution. Ship owners, on the other hand, can use the identified inventories to get precise prediction on the actual pollution their vessels cause to the environment during various modes of operation so that they can take adequate measures to minimize the penalties imposed by regulatory bodies.

There are four obvious alternatives to the above-formulated policy:

a) To use inventory methods selected by the policy makers without the benefit of verifying them with real measurement for each ship. As it was demonstrated by our case study, this method will almost surely produce shipping emission estimate with low precision. Therefore, the policy changes will most likely be inadequate. In fact, that is the situation now.

b) To regulate that every vessel should acquire and maintain its own measurement devices. They may even design their own family of inventories and justify their applicability for the ships they operate. That alternative would be unreasonably expensive for the ship owners, and very impractical because of the many problems that may arise when the machine crew starts interacting with the emission measurement system. As a result, even if the latter works in a given moment of time, the measurement results will be highly unreliable. Furthermore, the maritime and environmental authorities will use their own measurement systems rather than utilizing those on the ship (due to their necessity to comply with strict international regulations).

c) To require that every vessel should develop ship-specific inventories based on an on-board measurement campaign. This problem is almost impossible mathematically, because the data to create the inventory models will never be enough. On top, the policy makers would have a hard time dealing with so many different unknown models instead of using several known inventories. As a result, the assessed shipping emissions will be with even greater error than they are today.

d) To use only empirical data from on-board measurements. The main disadvantage of that strategy is that the best inventories, for a specific ship and type of operation contain prior knowledge, which will not be utilized. Additionally, the problems with the policy makers will be the same as in the previous alternative.

It seems that neither one of the discussed alternatives is satisfactory.

Based on the arguments given in the current section we propose the following policy for estimating the shipping emissions for future implementation:

Regulate that on-board emission measurements of nitrogen oxides, sulphur oxides, carbon dioxide, carbon monoxide, hydrocarbon, and particulate matter should be conducted for each vessel when put in exploitation and during every regular repair. For each possible inventory method, the deviations of its predicted emissions from the 
measured emissions for the different modes of operations should be calculated. Those results should be kept within the official vessel's documents and should be available to the regulating authorities.

Using the available deviations, any authority can identify the best inventory family for each of the three modes of operations, depending on their preferences encoded in the six-attribute value function. Those vessel-specific inventory families will ensure cheap and relatively precise estimation of the primary emissions from shipping both locally and globally.

\section{Conclusion}

In the paper, a case study was presented about measurement and prediction of the emission from a 27000 GRT bulk carrier, with slow speed diesel main engine and with medium speed diesel auxiliary engines.

During an on-board experimental campaign, the following measurements were taken:

a) $\mathrm{NO}_{\mathrm{x}}, \mathrm{SO}_{\mathrm{x}}, \mathrm{CO}_{2}, \mathrm{CO}, \mathrm{HC}$, and $\mathrm{PM}$ emission rates from the main engines when the vessel is at-berth, during maneuvering, and during cruising.

b) $\mathrm{NO}_{x}, \mathrm{SO}_{x}, \mathrm{CO}_{2}$, and $\mathrm{CO}$ emission rates from the auxiliary engines when the vessel is at-berth

c) The instantaneous engine power, the shaft speed, the specific oil consumption, the air consumption, and the exhaust mass flow rate for each of the four experiments described a) and b).

The measured emission rates were converted to instantaneous emission factors and eventually to total emission amounts. The latter were predicted with 13 families of emission inventories (Tier I-III, ENTEC, MEET, STEAM, MOPSEA, IMO, SMED, EMS, US EPA, NERI and Corbett) and prediction deviations have been calculated. A procedure was advised for estimating the prediction inventory deviations of the combined hourly emission amounts from the main engine plus the auxiliary engines. The best inventory families were identified using the minimal mean absolute deviation criterion. The best inventory method at berth happened to be MOPSEA (32.2\% mean absolute deviation), for maneuvering the best inventory family was MOPSEA (with 39.6\% mean absolute deviation), and for cruising the best inventory family is MEET (with 59.2\% mean absolute deviation). However, some of the other inventories produce unacceptably great deviation, well above $100 \%$.

A more rational procedure for inventory ranking was considered, where each inventory family has been formalized as a six-dimensional vector of prediction deviations for a given mode of operation, which treats the missing value problem and constructs a six-attribute value function. We proposed an algorithm to impute missing values in the vectors (in case some of the emission deviations were not calculated), and to construct a six-attribute value function. The calculation of the value function at the six-dimensional vectors of prediction deviations was in position more rationally to identify the best inventory family when the vessel is at-berth, during maneuvering, and during cruising. The relation between the minimal mean absolute deviation criterion ranking and the maximal value function criterion was investigated. It was demonstrated that the former is a "quick and dirty" special case of the latter.

The implications of the case study were used to advise novel future policy for cost-effective and reliable emission estimation caused by the shipping.

\section{Acknowledgments}

The authors would like to express special thanks to the National Centre for Maritime Engineering and Hydrodynamic of the Australian Maritime College (University of Tasmania), as well as to our colleagues from the Queensland University of Technology - Thuy Chu Van, Richard Brown and Zoran Ristovski - for the strong support of this study. We also acknowledge and express gratitude to the Port of Brisbane Corporation for their generous cooperation, as well as to Maritime Safety Queensland and to stevedore operators AAT, Patricks and DP World for their contribution to this study.

\section{Funding}

The authors received no direct funding for this research. 


\section{Citation information}

Jahangiri, S., Nikolova, N., \& Tenekedjiev, K. (2018). Empirical testing of inventories applying on-board measurements of exhaust emissions at port and at sea. Journal of Sustainable Development of Transport and Logistics, 3(2), 6-33. doi:10.14254/jsdtl.2018.3-2.1.

\section{References}

Acock, A.C. (2005). Working with Missing Values. Journal of Marriage and Family, 67(4), 1012-1016.

Agrawal, H., Malloy, Q. G. J., Welch, W. A., Miller, J. W., \& Cocker, D. R. (2008). In-use gaseous and particulate matter emissions from a modern ocean going container vessel. Atmospheric Environment, 42(21), 5504-5510.

Browning, L., \& Bailey, K. (2006). Current Methodologies and Best Practices for Preparing Port Emission Inventories, 15th International Emission Inventory Conference "Reinventing Inventories - New Ideas in New Orleans", New Orleans, May 15 - 18, 1-20.

Cappa, C. D., Williams, E. J., Lack, D. A., Buffaloe, G. M., Coffman, D., Hayden, K. L., et al. (2014). A case study into the measurement of ship emissions from plume intercepts of the NOAA ship Miller Freeman. Atmospheric Chemistry and Physics, 14(3), 1337-1352.

Chen, G., Huey, L. G., Trainer, M., Nicks, D., Corbett, J. J., Ryerson, et al. (2005). An investigation of the chemistry of ship emission plumes during ITCT 2002. Journal of Geophysical Research-Atmospheres, 110(D10), D10S90, doi: 10.1029/2004JD005236.

Cohen, J., Cohen, P., West, S., \& Aiken, L. (2003). Applied multiple regression/correction analysis for the behavioral sciences, Third Edition, Mahwah, NJ: Erlbaum.

Cooper, D. A. (2001). Exhaust emissions from high speed passenger ferries. Atmospheric Environment, 35(24), 4189-4200.

Cooper, D. A. (2003). Exhaust emissions from ships at berth. Atmospheric Environment, 37(27), 3817-3830.

Cooper, D. A., \& Andreasson, K. (1999). Predictive NOx emission monitoring on board a passenger ferry. Atmospheric Environment, 33(28), 4637-4650.

Cooper, D. A., Peterson, K., \& Simpson, D. (1996). Hydrocarbon, PAH and PCB emissions from ferries: A case study in the Skagerak-Kattegatt-Oresund region. Atmospheric Environment, 30(14), 2463-2473.

Cooper, D., \& Gustafsson, T. (2004). SCB: Methodology for calculating emissions from ships: 1. Update of emission factors. SMHI Swedish Meteorological and Hydrological Institute (publisher), Report series SMED and SMED\&SLU, No. 4.

Corbett, J. J., \& Fischbeck, P. (1997). Emissions from ships. Science, 278(5339), 823-824.

Corbett, J. J., \& Koehler, H. W. (2003). Updated emissions from ocean shipping. Journal of Geophysical ResearchAtmospheres, 108(D20), 4650-4666.

Corbett, J. J., Winebrake, J. J., Green, E. H., Kasibhatla, P., Eyring, V., \& Lauer, A. (2007). Mortality from ship emissions: A global assessment. Environmental Science \& Technology, 41(24), 8512-8518.

Dalsoren, S. B., Eide, M. S., Endresen, O., Mjelde, A., Gravir, G., \& Isaksen, I. S. A. (2009). Update on emissions and environmental impacts from the international fleet of ships: The contribution from major ship types and ports. Atmospheric Chemistry and Physics, 9(6), 2171-2194.

Deniz, C., \& Kilic, A. (2010). Estimation and assessment of shipping emissions in the region of Ambarli Port, Turkey. Environmental Progress \& Sustainable Energy, 29(1), 107-115.

Du, Y. Q., Chen, Q. S., Quan, X. W., Long, L., \& Fung, R. Y. K. (2011). Berth allocation considering fuel consumption and vessel emissions. Transportation Research Part E-Logistics and Transportation Review, 47(6), 1021-1037. 
Endresen, O., Sorgard, E., Behrens, H. L., Brett, P. O., \& Isaksen, I. S. A. (2007). A historical reconstruction of ships' fuel consumption and emissions. Journal of Geophysical Research-Atmospheres, 112(D12), D12301, doi:10.1029/2006JD007630.

Endresen, O., Sorgard, E., Sundet, J. K., Dalsoren, S. B., Isaksen, I. S. A., Berglen, T. F., \& Gravir, G. (2003). Emission from international sea transportation and environmental impact. Journal of Geophysical Research-Atmospheres, 108(D17), 4560, doi: 10.1029/2002JD002898

ENTEC. (2007). Ship emissions inventory - Mediterranean Sea. Concawe Review, 16(1), 8-10.

EPA. (2010). Control of emissions from new marine compression-ignition engines at or above 30 liters per cylinder. A Proposed Rule by the Environmental Protection Agency on 08/28/2009, 44441-44595

Eyring, V., Kohler, H. W., Van Aardenne, J., \& Lauer, A. (2005). Emissions from international shipping: 1. The last 50 years. Journal of Geophysical Research-Atmospheres, 110(D17305), doi: 10.1029/2004JD00561

French, S. (1993). Decision theory: an introduction to the mathematics of rationality. UK: Ellis Horwood.

French, S. \& Insua, D.R. (2010). Statistical Decision Theory, Kendall's Library of Statistics 9, Wiley.

Fu, M. L., Ding, Y., Ge, Y. S., Yu, L. X., Yin, H., Ye, W. T., \& Liang, B. (2013). Real-world emissions of inland ships on the Grand Canal, China. Atmospheric Environment, 81, 222-229.

Goldsworthy, L., \& Galbally, I. E. (2011). Ship engine exhaust emissions in waters around Australia: An overview. Air Quality and Climate Change, 45(4), 24.

Goldsworthy, L., \& Goldsworthy, B. (2015). Modelling of ship engine exhaust emissions in ports and extensive coastal waters based on terrestrial AIS data: An Australian case study. Environmental Modelling \& Software, 63, $45-60$.

Gommers, A., Verbeeck, L., Cleemput, E. V., Schrooten, L., \& De Vlieger, I. (2007). Monitoring programme on air pollution from sea-going vessels EV/43 (MOPSEA) Part 2: Global change, ecosystems and biodiversity, Scientific support plan for a sustainable development policy (SPSD II), Belgian Science Policy.

Hallquist, A. M., Fridell, E., Westerlund, J., \& Hallquist, M. (2013). On-board measurements of nanoparticles from a SCR-equipped marine diesel engine. Environmental Science \& Technology, 47(2), 773-780.

Hickman, J., Hassel, D., Joumard, R., Samaraz, Z. \&Sorenson, S. (1999) Methodology for calculating transport emissions and energy consumption (MEET), Transport Research Board, The National Academies of Sciences, Engineering, and Medicine, USA.

Hockstad, L. \& Hanel, L. (2018) Inventory of U.S. Greenhouse Gas Emissions and Sinks. United States: N. p., 2018. Web. doi:10.15485/1464240.

IMO. (2010). Report of the marine environment protection committee on its sixty-first session, MEPC 61/24/Corr.3

IMO. (2014). Reduction of GHG emissions from ships, third IMO GHG study, final report.

Jalkanen, J. P., Brink, A., Kalli, J., Pettersson, H., Kukkonen, J., \& Stipa, T. (2009). A modelling system for the exhaust emissions of marine traffic and its application in the Baltic Sea area. Atmospheric Chemistry and Physics, 9(23), 9209-9223.

Jalkanen, J. P., Johansson, L., Kukkonen, J., Brink, A., Kalli, J., \& Stipa, T. (2012). Extension of an assessment model of ship traffic exhaust emissions for particulate matter and carbon moNOxide. Atmospheric Chemistry and Physics, 12(5), 2641-2659.

Kasper, A., Aufdenblatten, S., Forss, A., Mohr, M., \& Burtscher, H. (2007). Particulate emissions from a low-speed marine diesel engine. Aerosol Science and Technology, 41(1), 24-32.

Keeney, R. L. \& Raiffa, H. (1993). Decisions with multiple objectives: preference and value tradeoffs. Cambridge University Press. 
Kilic, A., \& Deniz, C. (2010). Inventory of shipping emissions in Izmit Gulf, Turkey. Environmental Progress \& Sustainable Energy, 29(2), 221-232.

Kim, S., Hwang, J. W., \& Lee, C. S. (2010). Experiments and modeling on droplet motion and atomization of diesel and bio-diesel fuels in a cross-flowed air stream. International Journal of Heat and Fluid Flow, 31(4), 667-679.

Kristensen, H. O. (2010). Energy demand and exhaust gas emissions of marine engines. Technical University of Denmark.

Lu, G., Brook, J. R., Alfarra, M. R., Anlauf, K., Leaitch, W. R., Sharma, S., \& Phinney, L (2006). Identification and characterization of inland ship plumes over Vancouver, BC. Atmospheric Environment, 40(15), 2767-2782.

Lyyranen, J., Jokiniemi, J., Kauppinen, E. I., \& Joutsensaari, J. (1999). Aerosol characterisation in medium-speed diesel engines operating with heavy fuel oils. Journal of Aerosol Science, 30(6), 771-784.

Martínez de Osés, X. \& La Castells, M. (2010). Emission models: A comparison to determine the impact of maritime transport on emissions in SW European short sea shipping. No 207470, Proc. 51st Annual Transportation Research Forum, Arlington, Virginia, March 11-13, Transportation Research Forum

Merk, O. (2014). Shipping emissions in ports, International Transport Forum (Paris, France) Discussion Paper No. 2014-20, OECD/ITF.

Michaelowa, A. (2000). The Kyoto Protocol. Ecological Economics, 34(1), 155-156.

Miola, A., \& Ciuffo, B. (2011).Estimating air emissions from ships: Meta-analysis of modelling approaches and available data sources. Atmospheric Environment, 45(13), 2242-2251.

Moreno-Gutierrez, J., Calderay, F., Saborido, N., Boile, M., Valero, R. R., \& Duran-Grados, V. (2015). Methodologies for estimating shipping emissions and energy consumption: A comparative analysis of current methods. Energy, 86, 603-616.

Nikolova, N.D., Hirota, K., Kobashikawa, C., \& Tenekedjiev, K. (2006). Elicitation of non-monotonic preferences of a fuzzy rational decision maker. Information Technologies and Control, Year IV, Volume 1, 36-50.

Nikolova, N.D., Toneva-Zheynova, D., Naydenov, D., Tenekedjiev, K. (2012). Imputing missing values of environmental multi-dimensional vectors using a modified Roweis algorithm, Proc. IFAC Workshop on Dynamics and Control in Agriculture and Food Processing, 3-16 June, Plovdiv, Bulgaria, 199-205.

OECD. (1997). The OECD report on regulatory reform synthesis. Organisation for Economic Co-operation and Development, France.

Olesen, H. R., Winther, M., Ellermann, T., Christensen, J., \& Plejdrup, M. (2009). Ship emissions and air pollution in Denmark: Present situation and future scenarios, National Environmental Research Institute Aarhus University, Environmental Project No. 13072009 Miljøprojekt.

Petzold, A., Hasselbach, J., Lauer, P., Baumann, R., Franke, K., Gurk, C. \& Weingartner, E (2008). Experimental studies on particle emissions from cruising ship, their characteristic properties, transformation and atmospheric lifetime in the marine boundary layer. Atmospheric Chemistry and Physics, 8(9), 2387-2403.

Petzold, L.A., Weinzierl, B., Fiebig, M., Lichtenstern, M., Lauer, P., Gurk, C., Franke, K., \& Weingartner, E. (2006). Particle emissions from ship engines: emission properties and transformation in the marine boundary layer, Proceedings of the TAC-Conference, 26-29 June, Oxford, UK, pp. 78-82.

Radischat, C., Sippula, O., Stengel, B., Klingbeil, S., Sklorz, M., Rabe, R. \& Zimmermann, R (2015). Real-time analysis of organic compounds in ship engine aerosol emissions using resonance-enhanced multiphoton ionisation and proton transfer mass spectrometry. Analytical and Bioanalytical Chemistry, 407(20), 5939-5951.

Sinha, P., Hobbs, P. V., Yokelson, R. J., Bertschi, I. T., Blake, D. R., Simpson, I. J. \& Novakov, T (2003). Emissions of trace gases and particles from savanna fires in southern Africa. Journal of Geophysical Research-Atmospheres, 108(D13). 
Skjølsvik, K.O., Andersen, A. B., Corbett, J. J., \& Skjelvik, J. M. (2000). Study of greenhouse gas emissions from ships (report to International Maritime Organization on the outcome of the IMO Study on Greenhouse Gas Emissions from Ships), M.S.G.C.M.U. MEPC 45/8. Center for Economic Analysis/Det Norske Veritas, Trondheim, Norway.

Trozzi, C., \& De Lauretis, R. (2013). International navigation, national navigation, national fishing, EMEP/EEA emission inventory guidebook.

United Nations conference on trade and development - UNCTAD. (2014). Review of maritime transport. UNCTAD/RMT/2014, United Nations Publication Sales no. E.14.II.D.5.

Van der Gon, H.D., \& Hulskotte, J. (2010) Methodologies for estimating shipping emissions in Netherlands, Netherlands Research Program on Particulate Matter.

Wang, C., Corbett, J. J., \& Firestone, J. (2000). Improving spatial representation of global ship emissions inventories. Environmental Science \& Technology, 42(1), 193-199.

Winnes, H., \& Fridell, E. (2009). Particle emissions from ships: Dependence on fuel type. Journal of the Air \& Waste Management Association, 59(12), 1391-1398.

Wright, A. (1997). Marine diesel engine particulate emissions. Transactions of the Institute of Marine Engineers, 109, 345-364.

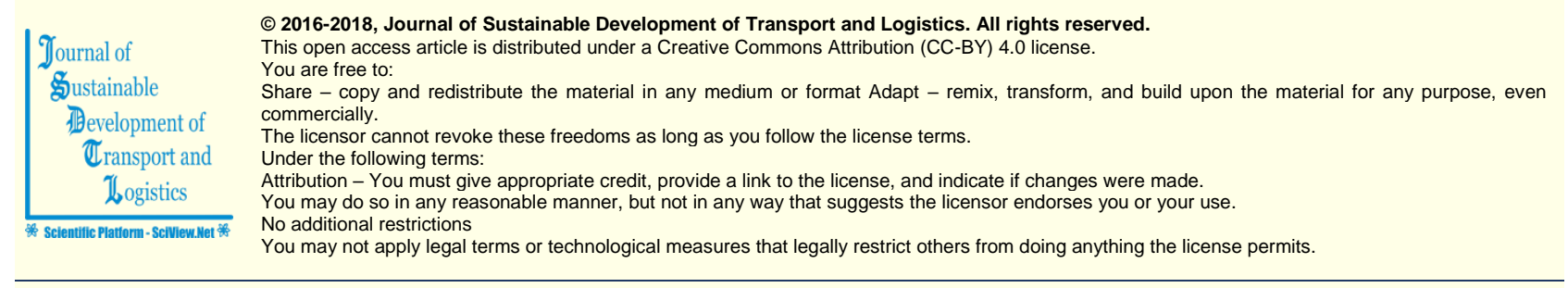

Journal of Sustainable Development of Transport and Logistics (ISSN: 2520-2979) is published by Scientific Publishing House "CSR", Poland, EU and Scientific Publishing House "SciView", Poland, EU

Publishing with JSDTL ensures:

- Immediate, universal access to your article on publication

- High visibility and discoverability via the JSDTL website

- Rapid publication

- Guaranteed legacy preservation of your article

- Discounts and waivers for authors in developing regions

Submit your manuscript to a JSDTL at https://jsdtl.sciview.net/ or submit.jsdtl@sciview.net 